\title{
Preventing the risks of monotony related fatigue while driving through gamification
}

\author{
Lukas Bier, Michael Emele, Kaja Gut, Jasna Kulenovic, David Rzany, Max Peter and Bettina Abendroth* (i)
}

\begin{abstract}
Background: Driving fatigue can have serious consequences. Too often fatal accidents are caused by fatigue. However, it is not uncommon for fatigue to occur while driving when the driver is under-challenged. Due to the increasing automation of vehicles, it is foreseeable that the number of accidents caused by monotony will increase. Interactions between driver and vehicle through gamification can remedy the situation and provide the driver with new stimuli during an otherwise monotonous journey.

Methods: In order to test the effectiveness of such interactions, we conducted a driving simulator study with 31 test persons to investigate driving performance and psycho-physiological parameters. Each subject ran through the experiment three times in randomized order to test the interaction system in comparison to a ride in which the driver was alone and a ride in which the driver had a co-driver.

Results: The results provide clear indications of safer driving of the test subjects when driving with gamification and with a passenger. The tested interaction system prevents upcoming fatigue in a similar way to communication with a passenger. The experiments also provide insights into the effects of monotony in vehicle driving.
\end{abstract}

Keywords: Monotony, Fatigue, Gamification, Human-computer interaction, Driving, Simulator

\section{Introduction}

As today's automobiles become increasingly automated, more and more tasks are taken from the driver. Examples of this are assistance systems such as cruise control, lane keeping as well as automatic braking and parking systems. On this basis, the actual driving task continuously changes into autonomous driving over time. Consequently, more and more road users rely on the systems implemented in the vehicle, which in turn leads to a lower focus on the actual driving task [105]. As a result of reduced mental activity, under-utilisation can result in passive task-related fatigue [59]. As the journey progresses, drivers initially become more inattentive and ultimately more tired $[50,69,70,73,74,93,95]$. This fatigue can lead to accidents. Every year more than one million people die in car accidents worldwide [103]. Various studies assume that $10-20 \%$ of all accidents are fatigue-related and that they account for an even larger proportion of fatal accidents $[69,83,95]$. It is particularly important for professional drivers and other

\footnotetext{
* Correspondence: abendroth@iad.tu-darmstadt.de

Institute of Ergonomics \& Human Factors, Technische Universität Darmstadt, Otto-Berndt-Straße 2, 64287 Darmstadt, Germany
}

persons who drive long distances to remain alert for the duration of their journey [74]. The under-utilisation that leads to fatigue results from driving through familiar or particularly monotonous driving scenarios. Monotony driving is defined as long motorway journeys, journeys at night [52], in low traffic, with few curves, constant noise levels and monotonous surroundings, such as roads surrounded by noise barriers and deserts [59]. Ultimately, the under-utilisation can be attributed to the persistent lack of new stimuli.

The declared aim of this study is to enrich the driving task with new stimuli in order to prevent the driver's performance from constantly declining and ultimately preventing the driver from losing sight of the driving task altogether. It has been proven that new stimuli or an increase in mental strain [101], such as those offered by co-drivers [20, 99], increase driving performance. According to the studies by Markey et al. [58], four aspects have to be considered to continuously engage drivers. The challenge has to be increased, performance feedback has to be given, social recognition has to be offered and finally an incentive system for the driver has to be created. The implementation of these aspects takes place 
through the gamification of the driving task. Gamification refers to the integration of playful elements into a non-playful context [17].

Gamification has already contributed to a general improvement in performance in other contexts, for example in the education and health sector $[34,86]$.

In detail, an interaction system was developed that actively influences the driving task by giving real-time challenges for the driver with regard to lane keeping, speed keeping and distance keeping, as well as rewarding increased attention to the vehicle environment by quiz questions about the vehicle environment. The new stimuli are not only visual, but also auditory and verbal, since a voice control was implemented.

The goal of this research was to investigate the effects of the system on the driver's monotonous fatigue and thus also on his driving performance and safety.

In order to better understand the course of monotonous fatigue and its effects, a comparison was made with a solo ride.

In the further course of this article, the methodology of how monotony was induced and how fatigue was measured is presented on the one hand and the results are presented and discussed on the other hand. The contribution thus provides insights into how monotonic fatigue can be prevented without distracting the driver from the actual driving task by a secondary task.

\section{Related work}

\subsection{Causes and effects of fatigue}

Fatigue results from a task-related continuous strain. It is irrelevant whether the strain is too low or too high, since the effects are equal [46].

Fatigue as such can depend on various causes, which can occur individually or collectively. The degree of fatigue depends mainly on the duration of the existing causes. The symptoms on a physical and psychological level can be represented as follows. Physically, fatigue leads to disorders of motor and sensorimotor coordination, such as a decrease in the precision of cyclically recurring movements, a flattening of breathing and a change in cardiovascular activity, such as a pulse acceleration or deceleration. Psychologically, there are reception, perception and coordination disorders as well as a decrease in concentration, attention and thinking skills, unwillingness to work, irritability and the subjective feeling of tiredness $([8,46])$. Fatigue should not be equated with sleepiness, as the latter is due to a lack of sleep and is reversible only through sleep. Fatigue, on the other hand, can be countered by changing the over- or underchallenging task [59].

Fatigue is measured either through the activity itself (reduction in performance, more mistakes) or through reactions before/during/after the activity [8].

\subsection{Intervention against fatigue}

Measures against fatigue have not yet been technically introduced in the automotive industry; currently implemented warning systems only indicate increased fatigue. Nevertheless, there are various studies that have devoted themselves to reducing fatigue and have investigated the influence of various countermeasures. In the literature, a fundamental distinction has been made in this context between behavioural and relational prevention measures [16, 102].

Relational prevention against fatigue requires measures of a technical or organisational nature. These change the conditions for the driver in a way that reduces or eliminates the fatiguing effect of the driving situation. Behavioural prevention, on the other hand, refers to measures taken by the driver personally to prevent fatigue.

Studies on behavioural prevention investigated the effects of short breaks [32], caffeine consumption [57], food intake [32] and exercise [39, 41]. A positive effect on the state of fatigue could be proven for all measures. However, for the implementation of the measures it is either necessary to interrupt the driving task or the duration of the effect is very short (10-20 min) (cf. [32]).

Studies prove that relational prevention can also lead to a reduction of the measurable fatigue effects by certain light settings [76], temperature settings [84, 92], but also by ventilation [32] and acoustic irradiation [4, 32]. Here it can also be seen, however, that the reduction in temperature, for example, could lead to more alerted test persons for a short time, but that the fatigue effects reappear quickly. This can be attributed to the fact that the actual task of the test person remains monotonous and the adaptation of the environment only provides new stimuli for a short time.

Finally, there is the option to adjust the driver's task so that new stimuli are set. This can be done by a secondary task or by adjusting the driving task itself.

Verwey and Zaidel [98] let test persons interact with a gamebox, which combined trivia quiz questions and a Tetris game. In a monotonous test ride, significant improvements in driving performance were observed. However, the gamebox bears the danger of completely turning the driver away from the driving task and thus poses a new safety risk.

Steinberger et al. [89] used a reward game in short driving tests of $20 \mathrm{~min}$ to influence the driver's speed attitude. A particularly precise adherence to the speed was rewarded and presented playfully on a Head-Up-Display (HUD). The results obtained in this experiment suggest that gamification reduces boredom significantly.

Based on these findings, a driving game was developed for this study that takes up and expands the idea of Steinberger et al. [89]. It was also tested whether the positive effects could be confirmed on long journeys, as the test by Steinberger et al. [89] lasted only $20 \mathrm{~min}$. 


\section{Method}

\subsection{Apparatus}

The institute's own static driving simulator was used for the test series. The simulation environment is generated with the driving simulation program SILAB 5.1 and is realized by a simultaneous projection of six beamers onto six associated screens (see Fig. 1). This setup ensures a realistic $360^{\circ}$ panoramic view.

The vehicle used is an original Chevrolet Aveo body with a fully-fledged interior and full range of functions. All mirrors and the seat position are freely adjustable and can be adapted to the respective needs of the various test participants. The vehicle is designed as an automatic system and controlled via brake pedal, accelerator pedal and steering wheel. The driving noises are simulated using speakers mounted in the vehicle. The data recording rate is $60 \mathrm{~Hz}$.

\subsection{Driving scenario and boredom induction}

There is no general definition of a monotonous driving situation in the literature. Driving test routes are often designed without any traffic or curves. However, since this route design leads to extremely unrealistic driving scenarios, limit values of a monotonous route design were first identified by a literature search. In order to define the characteristics of a monotonous driving situation, a detailed literature search of studies on driver fatigue was carried out and the core information on their route design was collected according to a specially created categorisation for route modelling (see Table 1). For the three main influencing groups of route, landscape and traffic, all integrated influencing factors were quantitatively analysed and thus intervals and limit values were defined which, if adhered to, would be highly likely to lead to a fatigue-promoting driving situation (Table 2). In total, the route designs of 32 studies in which monotonous fatigue could be detected were analysed and summarised.

The design of the simulation route follows the principle "as monotonous as necessary, as varied as possible" in order to guarantee the primary goal of generating fatigue during the driving task while ensuring a realistic driving experience as well as sufficient possibilities for environment-dependent driving games and measuring methods. Finally, a $240 \mathrm{~km}$ long motorway section of the German motorway A5 was selected and simulated as a route, which fulfils the researched criteria from Table 2. This procedure ensures that the simulated route satisfies the requirement of depicting a real driving scenario. An illustration of the simulated route can be seen in Fig. 2 for three route sections.

\subsection{Monotony intervention}

The interaction system developed [9] consists of a headup display (5-in.) and a centre console display (12-in.). The HUD is visible to the test person on the windscreen as a reflection of a smartphone screen and is only active during interactions.

The game contains a total of 3 types of driving games in which the test person is instructed to: maintain the lane as precisely as possible on straight stretches of the road; maintain the legal minimum distance to the vehicle in front as accurately as possible or maintain the current maximum speed as accurately as possible. All games are active for $1 \mathrm{~min}$ at a time and reward a particularly good goal achievement with points, which are summed up in a high score.

Thus, the driver is presented with a new challenge, which consists of the precise fulfilment of his general driving task. For the course of the driving game, the drive receives feedback on how well he is currently fulfilling his driving task (see Fig. 3 on the left). Social recognition is provided by the scoring system, which
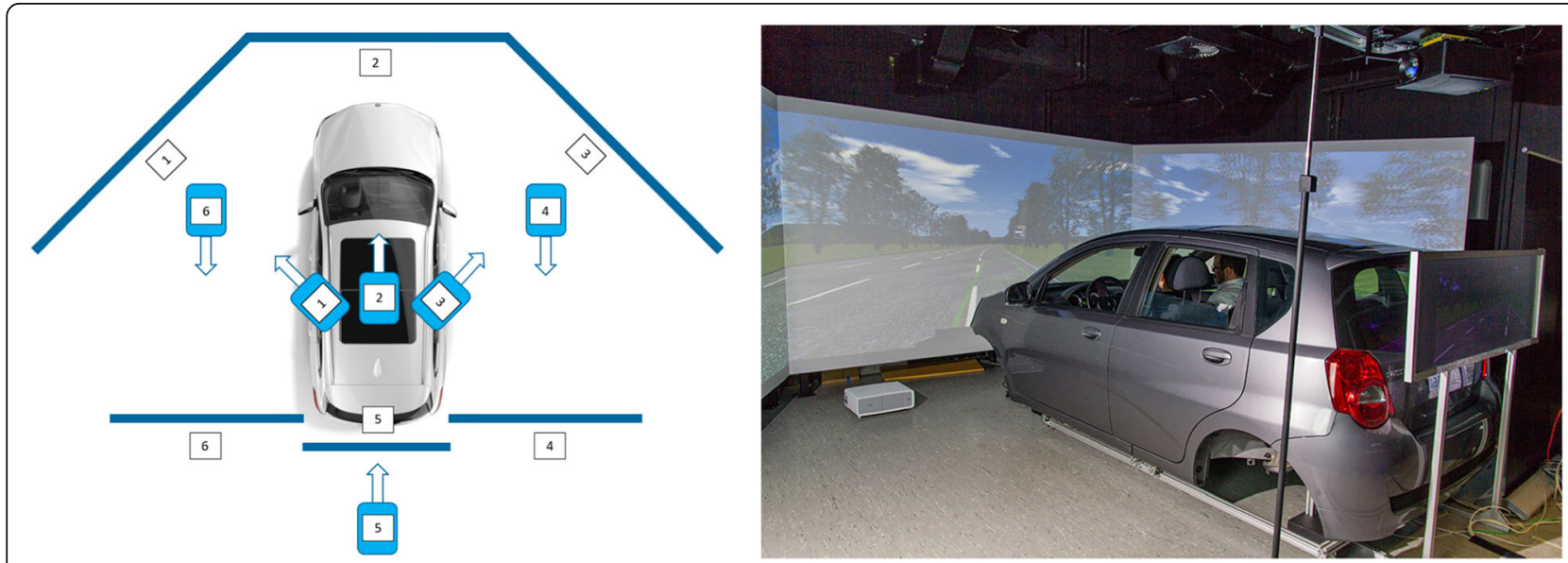

Fig. 1 Schematic structure of the used driving simulator 
Table 1 Information in researched studies on route design by category

\begin{tabular}{|c|c|c|c|c|c|c|c|c|c|}
\hline Author & $\begin{array}{l}\text { Track } \\
\text { layout }\end{array}$ & $\begin{array}{l}\text { Track } \\
\text { type }\end{array}$ & Connections & $\begin{array}{l}\text { Markings \& } \\
\text { Buildings }\end{array}$ & $\begin{array}{l}\text { Type of } \\
\text { landscape }\end{array}$ & Topography & Meteorology & $\begin{array}{l}\text { Traffic } \\
\text { density }\end{array}$ & $\begin{array}{l}\text { Traffic } \\
\text { participants }\end{array}$ \\
\hline $\begin{array}{l}\text { Åkerstedt, Peters, Anund, \& Kecklund, } \\
2005 \text { [2] }\end{array}$ & & $x$ & & & & & $x$ & $x$ & \\
\hline Arnedt, Wilde, Munt, \& MacLean, 2001 [5] & $x$ & $x$ & & $x$ & & & & $x$ & \\
\hline Atchley, Chan, \& Gregersen, 2014 [6] & $x$ & $x$ & & $x$ & & & & $x$ & \\
\hline Boyle, Tippin, Paul, \& Rizzo, 2008 [12] & $x$ & $x$ & & & & & & $x$ & \\
\hline Eoh, Chung, \& Kim, 2005 [22] & $x$ & $x$ & & & & & $x$ & $x$ & \\
\hline Fletcher, Petersson, \& Zelinsky, 2005 [25] & $x$ & $x$ & & & $x$ & & & & \\
\hline $\begin{array}{l}\text { Forsman, Vila, Short, Mott, \& van Dongen, } \\
2013 \text { [26] }\end{array}$ & $x$ & $x$ & & & $x$ & & $x$ & $x$ & $x$ \\
\hline Gastaldi, Rossi, \& Gecchele, 2014 [28] & $x$ & & & $x$ & $x$ & & & & \\
\hline Gershon, Shinar, \& Ronen, 2009 [29] & $x$ & $x$ & & & $x$ & & & & \\
\hline Greschner, 2011 [32] & & $x$ & $x$ & & & & $x$ & $x$ & \\
\hline $\begin{array}{l}\text { Hayami, Matsunaga, Shidoji, \& Matsuki, } \\
2002 \text { [37] }\end{array}$ & $x$ & & & & & & $x$ & $x$ & \\
\hline Horne \& Baulk, 2004 [40] & $x$ & $x$ & $x$ & $x$ & & & & $x$ & \\
\hline Horne, J. \& Reyner, L., $2001[39,41]$ & $x$ & $x$ & & $x$ & & & & $x$ & \\
\hline $\begin{array}{l}\text { Ingre, Akerstedt, Peters, Anund, \& Kecklund, } \\
2006 \text { [43] }\end{array}$ & & $x$ & & & & & $x$ & $x$ & \\
\hline Katja Karrer-Gauß, 2011 [46] & $x$ & $x$ & & $x$ & $x$ & $x$ & $x$ & $x$ & \\
\hline $\begin{array}{l}\text { Körber, Cingel, Zimmermann, \& Bengler, } \\
2015 \text { [48] }\end{array}$ & & $x$ & & & & & & $x$ & \\
\hline Larue et al., 2011 [52] & $x$ & $x$ & $x$ & $x$ & $x$ & $x$ & $x$ & $x$ & \\
\hline Lenné, Triggs, \& Redman, 1997 [53] & $x$ & $x$ & & & $x$ & $x$ & & $x$ & \\
\hline Liu, 2015 [55] & $x$ & $x$ & & $x$ & $x$ & $x$ & $x$ & $x$ & \\
\hline Merat \& Jamson, 2013 [62] & $x$ & $x$ & $x$ & & & & & $x$ & \\
\hline Mets et al., 2011 [63] & & $x$ & $x$ & & $x$ & $x$ & $x$ & $x$ & \\
\hline $\begin{array}{l}\text { Moller, Kayumov, Bulmash, Nhan, \& } \\
\text { Shapiro, } 2006 \text { [64] }\end{array}$ & $x$ & $x$ & & $x$ & & & & & \\
\hline Neubauer, Matthews, \& Saxby, 2014 [66] & $x$ & & & $x$ & $x$ & & & $x$ & \\
\hline Otmani, Pebayle, Roge, \& Muzet, 2005 [67] & $x$ & $x$ & $x$ & $x$ & $x$ & & $x$ & $x$ & \\
\hline Paul, Boyle, Tippin, \& Rizzo, 2005 [71] & $x$ & $x$ & & & & & & $x$ & \\
\hline $\begin{array}{l}\text { Rimini-Doering, Manstetten, Altmueller, } \\
\text { Ladstaetter, \& Mahler, } 2001 \text { [79] }\end{array}$ & $x$ & & & & & & $x$ & $x$ & $x$ \\
\hline Rossi, Gastaldi, \& Gecchele, 2011 [80] & & $x$ & & $x$ & $x$ & & $x$ & $x$ & \\
\hline $\begin{array}{l}\text { Saxby, Matthews, Hitchcock, \& Warm, } \\
2007 \text { [82] }\end{array}$ & $x$ & $x$ & $x$ & & $x$ & $x$ & & $x$ & $x$ \\
\hline Thiffault \& Bergeron, 2003 [93] & $x$ & $x$ & $x$ & $x$ & $x$ & & & $x$ & $x$ \\
\hline Ting, Hwang, Doong, \& Jeng, 2008 [94] & $x$ & $x$ & & $x$ & $x$ & $x$ & & $x$ & \\
\hline Valck \& Cluydts, 2001 [96] & $x$ & $x$ & & $x$ & & & & $x$ & \\
\hline Verwey \& Zaidel, 1999 [98] & $x$ & $x$ & & $x$ & $x$ & $x$ & $x$ & $x$ & \\
\hline
\end{tabular}

simultaneously rewards the driver (Fig. 3 right) and allows him to compare his performance with other drivers (Fig. 4 right). As a special incentive, the driver is promised a $50 €$ amazon shopping voucher at the start of the system in case he achieves the best performance among all participants. Therefore, all 4 requirements (challenge, performance feedback, social recognition and incentive) for a successful gamification by Markey et al. [58] are fulfilled.

Each driving game is followed by 3 quiz questions from a catalogue of 11 quiz questions, which animate the test person to verbal activity and encourage him to 
Table 2 Limit values of a monotonous route design

\begin{tabular}{|c|c|c|c|}
\hline & Category & Characteristic & Researched limit \\
\hline \multirow[t]{17}{*}{ TRACK } & \multirow[t]{5}{*}{ Track layout } & Length of straight sections & $4 \mathrm{~km}-\infty$ \\
\hline & & Number of curves & 0-20 pro $100 \mathrm{~km}$ \\
\hline & & Length of curves & $1 \mathrm{~km}-\infty$, but always smaller than the curve radius \\
\hline & & Radius of curves & $1 \mathrm{~km}-\infty$, but always at least as large as the curve length \\
\hline & & Vertical track routing & Perfectly flat \\
\hline & \multirow[t]{2}{*}{ Track type } & Track type & Country road, similar to a motorway or motorway \\
\hline & & Number of lanes in own driving direction & $(1-) 2$ \\
\hline & \multirow[t]{3}{*}{ Connections } & Junctions & Spacing $25-50 \mathrm{~km}$ \\
\hline & & Parking spaces & Not allowed \\
\hline & & Bridges & $\begin{array}{l}\text { In combination with each junction and another after } \\
\text { every second junction }\end{array}$ \\
\hline & \multirow[t]{7}{*}{ Markings \& Buildings } & Frequency of sign appearances & $6 \mathrm{~km}-\infty$ \\
\hline & & Type of signs & $\begin{array}{l}\text { No sign gantry; } \\
\text { Typical motorway signs on the roadside }\end{array}$ \\
\hline & & Road marking & Standard marking with dashed and solid white lines \\
\hline & & Emergency lane & Continuous right, $2.5 \mathrm{~m}$ wide \\
\hline & & Median crash barrier & Continuous with guard rail, reflector post, bushes \\
\hline & & Reflector post & Continuous on both sides, standard distance $50 \mathrm{~m}$ \\
\hline & & Crash barriers & $\begin{array}{l}\text { Left continuous; } \\
\text { Right optionally with constant length of } 4 \mathrm{~km}-\infty\end{array}$ \\
\hline \multirow[t]{10}{*}{ LANDSCAPE } & Topography & / & Plain landscape with horizon limitation \\
\hline & \multirow[t]{4}{*}{ Meteorology } & Weather & $\begin{array}{l}\text { No rainfall; } \\
\text { Sky blue - cloudy }\end{array}$ \\
\hline & & Daytime & Dawn or dusk \\
\hline & & Visibility & $2000 \mathrm{~m}$ \\
\hline & & Season & Summer or summer-like \\
\hline & \multirow[t]{5}{*}{ Type of landscape } & Tree density & $\begin{array}{l}\text { Low to moderate; } \\
\text { Accurate or randomly placed. }\end{array}$ \\
\hline & & Urban landscape & $\begin{array}{l}\text { Not exclusively; } \\
\text { Distance between distant houses or villages in rural area: } 6 \mathrm{~km}-\infty\end{array}$ \\
\hline & & Rural fields & Allowed \\
\hline & & Water bodies & Not allowed \\
\hline & & $\begin{array}{l}\text { Change frequency of landscape } \\
\text { types (per street side) }\end{array}$ & $\begin{array}{l}\text { Rural: } 25 \mathrm{~km}-\infty ; \\
\text { Forest: } 10 \mathrm{~km}-\infty ; \\
\text { Noise control: } 10 \mathrm{~km}\end{array}$ \\
\hline \multirow[t]{8}{*}{ TRAFFIC } & \multirow[t]{3}{*}{ Traffic participants } & Cars & Allowed \\
\hline & & Trucks & Use on half the slower vehicles \\
\hline & & Pedestrians & Not allowed \\
\hline & \multirow[t]{5}{*}{ Traffic density } & Faster vehicles: density & $\begin{array}{l}\text { 0-10 vehicles per hour; } \\
\text { In combination with slower vehicles: 0-6 vehicles } \\
\text { per hour }\end{array}$ \\
\hline & & $\begin{array}{l}\text { Faster vehicles: relative } \\
\text { velocity \& behaviour }\end{array}$ & $\begin{array}{l}\text { Unobtrusive behaviour; } \\
\text { Up to } 20 \mathrm{~km} / \mathrm{h} \text { above the permitted speed limit, } \\
\text { but strictly different from } 0 \mathrm{~km} / \mathrm{h}\end{array}$ \\
\hline & & Slower vehicles: density & $\begin{array}{l}\text { 0-10 vehicles per hour; } \\
\text { In combination with slower vehicles: } 0-6 \text { vehicles } \\
\text { per hour }\end{array}$ \\
\hline & & $\begin{array}{l}\text { Slower vehicles: relative } \\
\text { velocity \& behaviour }\end{array}$ & $\begin{array}{l}\text { Unobtrusive behaviour; } \\
\text { Up to } 20 \mathrm{~km} / \mathrm{h} \text { slower than the test person's } \\
\text { vehicle, but different from } 0 \mathrm{~km} / \mathrm{h}\end{array}$ \\
\hline & & Oncoming traffic & $0-20$ vehicles per hour \\
\hline
\end{tabular}



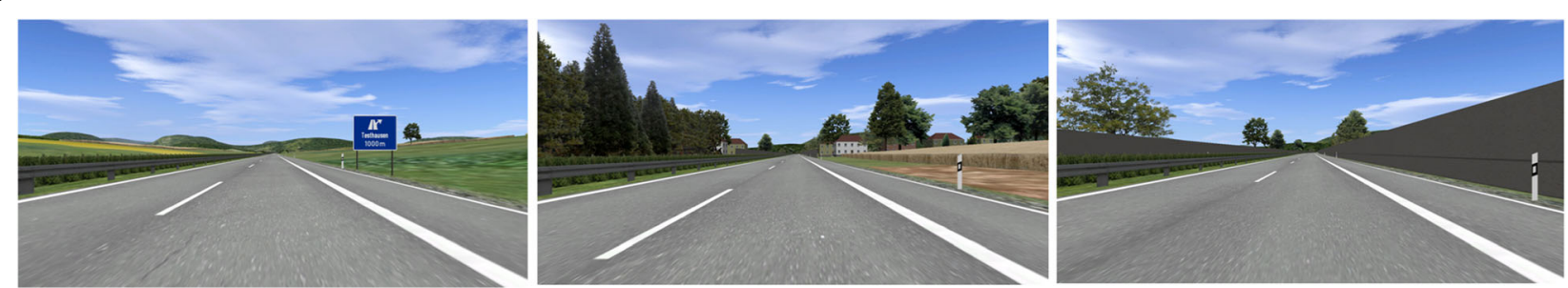

Fig. 2 Exemplary illustration of the route - cross-country (left) - rural (centre) - through town with noise protection (right)

concentrate on the driving route in the future. The following task serves as an example for such a question:

"Please guess the distance to the car ahead of you".

The question is presented to the driver via voice output, giving him a new auditory stimulus. He answers the question verbally to avoid turning his attention off the road on the one hand and to become mentally and physically active on the other. The dialogue between the driver and the interaction system ends the previously monotonous driving situation for the driver. The driver receives the feedback via the HUD, so that he does not have to turn his gaze away from the road. The points are given via voice output. The driver will quickly notice that the quiz questions are repeated and will therefore be motivated to pay more attention to the details in the vehicle environment that are all relevant for fulfilling the driving task. With this approach, the concept of Steinberger et al. [89], which only referred to speed and did not generate any verbal activity by the driver, was extended.

\subsection{Study design}

The study was designed as a within-sample in which the same subjects had to complete three runs. The resulting data sets were then compared with each other. Each test person drove one ride on his own as a baseline measurement, one ride with the interaction system and one ride with a human co-driver. The co-driver ride serves for comparison, as it is proven that a human co-driver breaks the monotony on motorway trips, motivates the driver and builds up pressure on the driver to perform $[7,19,32,42]$. The co-drivers were provided by the institute and conducted scripted conversations with the test persons in order to ensure comparability between the test persons. One third of the conversation time was spent talking about the test person, his work and his hobbies, one third about trivia and another third of the conversation time was spent playing driving games (e.g. I spy). The test persons went through the three $2.5 \mathrm{~h}$ rides in randomised order on three different days to exclude sequence effects.

\subsection{Participants}

A total of 37 volunteers took part in the study, 6 of which had to stop the experiments temporarily due to the simulator sickness [13]. This left 31 usable data sets and thus a similar or higher number of subjects compared to other studies ([52]; cf. [89, 94, 98]). Of these, 18 male and 13 female subjects were involved in the driving

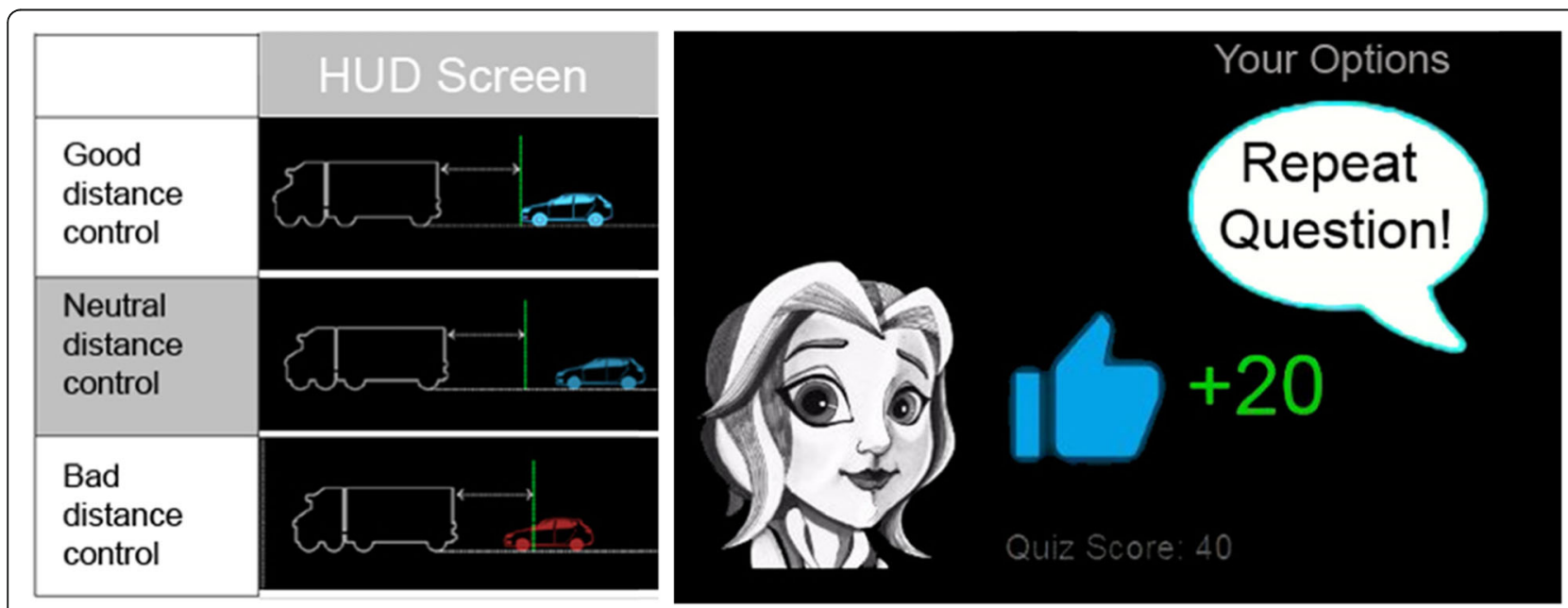

Fig. 3 Feedback via HUD (left) and centre console (right) during the driving game "keep distance" 


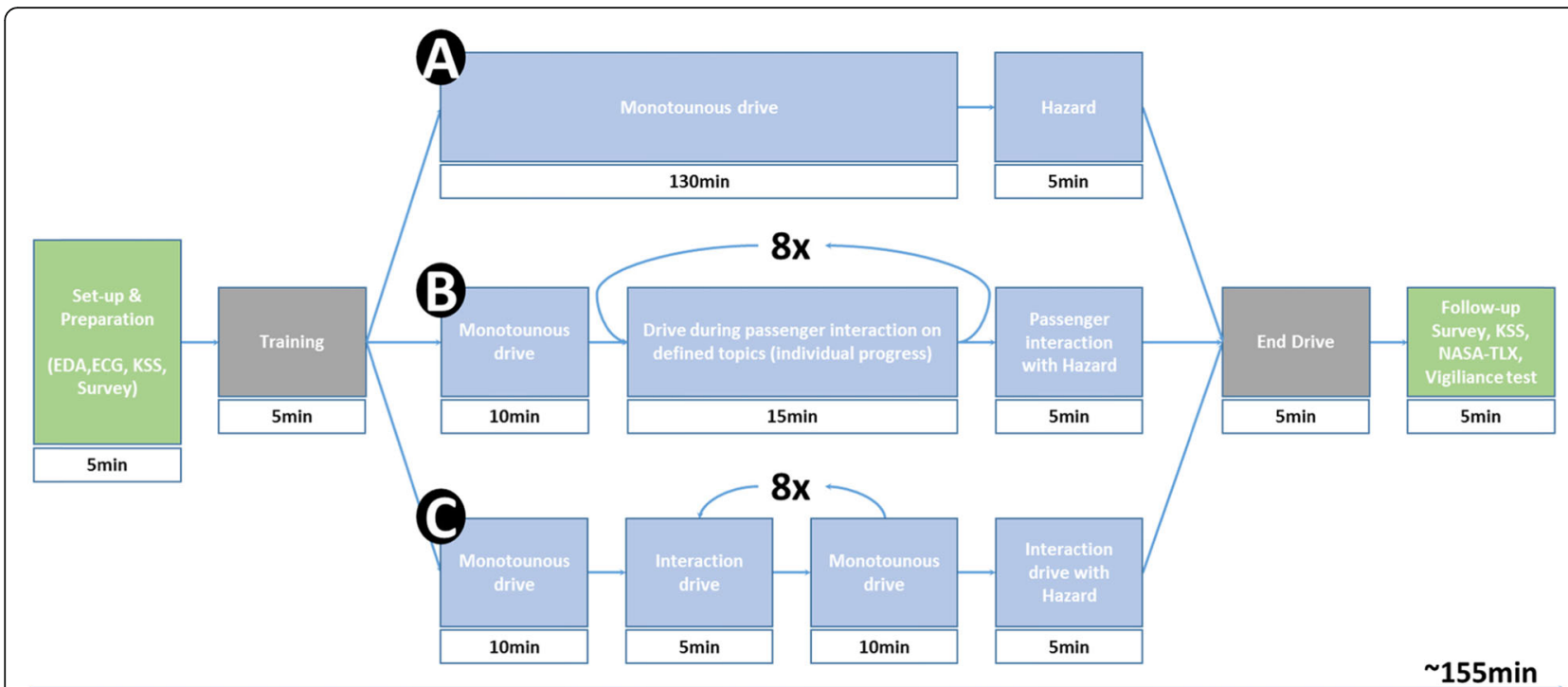

Fig. 4 Procedure of the driving tests

experiments. Some participants were recruited from the institute's pool of volunteers, while others were recruited from campus. Two men and two women indicated that they have already had experience with a driving simulator. All test persons had to be in possession of a valid driving licence. The test persons received $100 €$ after completion of the three journeys, if the tests were not finished, the test persons were compensated with $10 €$.

\subsection{Procedure}

Prior to the start of the driving tests, the test persons were briefed by telephone or e-mail that they should refrain from taking caffeine on the day of the tests and go to bed early the evening before in order to be able to take part in the tests well rested. The test persons also brought a filled-in questionnaire on their person (age, sex, driving experience and the Epworth-Sleepness-Scale [45]) to the first test date. There were two test slots to choose from. The first slot was scheduled from 08:3011:30 and the second slot from 12:00-15:00. The test persons completed all three experiments at intervals of at least 2 days in the same slot in order to exclude effects of the circadian rhythm on the experiment as far as possible. With more than 300 test hours on 55 test days, the trials covered the period from November 2017 to January 2018.

Before each journey, the test persons were taken to a preparation room. There they filled out the KarolinskaSleepiness Scale (KSS) [1] to record the state of fatigue before the start of the journey. They were also equipped with a Varioport system to measure electrocardio activity (ECG, 3 electrodes on the chest) and electrodermal activity (EDA, two non-polarizing silver electrodes on the left feed) which collected data with a $60 \mathrm{~Hz}$ scan rate. To avoid interference with the measurements, the test persons were asked to remove their mobile phones.

The test persons were then taken to the driving simulator, where the simulator functions were explained to them. Eye tracking glasses (SMI ETG 2) were applied to the test persons and set up using a 3-point calibration.

At the start of the journey, the test persons first drove a five-minute test section (see Fig. 4). The test section was simulated as a country road with many curves in order to familiarize the test persons with the simulator. In this section, subjects affected by the simulator sickness were able to determine whether they might have to stop the experiments.

Subsequently, the test persons drove onto the motorway from the country road and the test recording began. All three tests had the same route over $235 \mathrm{~km}$ of motorway. During the solo ride the test person was therefore alone for approx. $135 \mathrm{~min}$ and occupied with the driving task only. During the ride with the developed interaction system there were a total of nine sessions for which the interaction system was activated. Each session consisted of a driving game and 3 quiz questions which were mixed together from a catalogue of 11 quiz questions. Each subject performed the same driving tasks and answered the same questions at the same waypoints in order to ensure comparability of the experiments. An interaction session lasted about 5 minutes. The waypoints that triggered the interaction were about $15 \mathrm{~min}$ apart, so there was a break of about ten minutes between the interactions. The 10-min interval was previously chosen to ensure that the driver was offered new stimuli at not too long intervals (see [44]).

During the third ride, the test person drove together with a co-driver. The co-driver was unknown to the test 
person. Two different co-drivers shared the 31 rides with the test persons, addressing identical topics at the same time. The topic always changed at the same waypoints when a driving game was introduced on the interaction ride. The co-drivers received a signal via headphones that indicated the change of topic. In a total of nine sessions, topics from the areas of job, hobby and vacation of the test persons were discussed in the first three sessions. In the next three sessions, topics on general education from the fields of geography, famous personalities and music were addressed. In the last three sessions, games like "Who am I?" were played.

At kilometre 232, a dangerous situation was simulated on all journeys. Here, a wild boar crossed the lane of the test person $120 \mathrm{~m}$ in front of the vehicle. The hazard required a sharp braking manoeuvre or an evasive steering manoeuvre and was included as an attention test ([47]; cf. procedure by [89]). The road section before the hazard was simulated as dense woodland for several kilometres, so that the test persons could not memorize the exact spot.

After the respective driving test, the eye movement system was immediately removed and the test persons completed a NASA-TLX questionnaire, a KSS questionnaire and a vigilance test. The ECG and EDA electrodes were then removed. After driving with the developed interaction system, the test persons completed an additional acceptance questionnaire.

\subsection{Research questions}

The central research questions can be formulated as follows:

RQ1: How does the use of gamification in vehicle driving influence the development of subjective and objective psycho-physiological data and measurements compared to driving alone?

RQ2: How does the use of gamification in vehicle driving influence driving performance and safety compared to driving alone?

RQ3: Is the interaction system suitable for avoiding fatigue in the same way as a passenger during monotonous journeys?

\subsection{Measures}

Fatigue is not directly measurable, only its consequences. Since these can vary from person to person, however, a first difficulty regarding the interpretation is already apparent here. In order to be able to estimate the degree of fatigue, values must be known at which the performance decreases [51].

The measurement methods to identify fatigue where chosen through the review of Bier, Wolf, Hilsenbek and Abendroth [10]. A combination of measured values was chosen for the test. This includes values of subjective evaluation, psychophysiological excitement and driving performance.

\subsubsection{Subjective psycho-physiological measurements}

The subjective evaluation of the effectiveness of the interaction system was carried out under various aspects. On the one hand, it was necessary to find out whether the subjective fatigue assessment of the test persons showed a difference between the trials. On the other hand, it was to be investigated whether the strain of the test persons differed during the trials.

3.8.1.1 Fatigue assessment Both individual-centred instruments (unstructured interviews) and standardised measurement methods for subjective fatigue assessment are available. Since unstructured interviews are very time-consuming and do not offer a high degree of standardisation, a self-rating procedure is used to record sleepiness.

The used "Karolinska-Sleepiness-Scale (KSS)" is originally derived from the "Stanford Sleepiness Scale" by Hoddes et al. [38]. Before and after each simulation run, fatigue was measured using the Karolinska-SleepinessScale [1]. It is a nine-step scale, from " 1 - extremely alert" to "9 - very sleepy, great effort to keep awake, fighting sleep". The participant marks the appropriate number. According to Åkerstedt and Gillberg [1], the psychometric measurement methods for fatigue have a satisfactory, criterion-related validity. Although the scale was originally used to measure drowsiness, it can be used to measure fatigue [97], especially when the difference between pre- and post-sleep is used.

3.8.1.2 Subjective strain A German short version [30] of the NASA Task Load Index (NASA TLX, [36]) was used to measure strain. NASA TLX is the most widely used and established questionnaire for the evaluation of mental workload [33]. This was handed out to the test subjects after each simulation run. It measures the taskrelated, subjective strain in six dimensions: "mental demand", "physical demand", "temporal demand", "performance", "effort" and "frustration". "Mental demand", "physical demand" and "temporal demand" are subscales of the task characteristics. Behavioural characteristics include the subscales "performance" and "effort". "Frustration" serves as a subscale for individual characteristics. This version is a short form. In the longer version the dimensions are also compared with each other. Since the driving test already took a lot of time, the subsequent survey of the test persons was carried out as short and economic as possible. The individual requirements are evaluated on a 20 -step scale in the value range from 0 to 
100. The dimension is always evaluated from 0 for "low" to 100 for "high".

\subsubsection{Objective psycho-physiological measurements}

Two different measuring systems were used to measure psycho-physiological excitement. The electrodermal activity (EDA), the electrocardiography (ECG) and the blink frequency of the test persons were recorded. All parameters were recorded throughout the entire duration of the test. Eye tracking glasses from SMI (SMI ETG 2 System) were used to record the blink frequency and the Varioport system from Becker Meditec was used to record EDA and ECG.

3.8.2.1 Electrodermal activity (EDA) Electrodermal activity generally refers to bioelectrical phenomena in the skin that can be described physically as changes in conductivity, resistance and potential [100]. The measured electrodermal activity reflects the sweat production in the eccrine glands, which increases with growing excitation of the test persons and their nerve tracts and thus enhances skin conductivity [78].

The EDA was measured exosomatically via nonpolarizing silver electrodes in combination with an electrode paste applied to the electrodes with a content of $0.5 \% \mathrm{NaCl}$. According to the recommendations of Boucsein [11], the palmar and planar surfaces are particularly suitable as optimal conductors of the EDA. Since the steering movements were carried out with the hands, however, an attachment should be avoided due to an increased probability of movement artefacts. Thus, the left foot proved to be particularly suitable. Due to the automatic gearshift, it is not used while driving and is therefore available for measurements. The tonic skin conductance (SCL) was evaluated.

3.8.2.2 Electrocardiography (ECG) An electrocardiogram (ECG) is used to determine cardiac activity. The electric activity of the heart muscle fibres is recorded by electrodes attached to the human chest. The frequency of the heartbeat can be evaluated by identifying so-called $\mathrm{R}$ waves. The most frequently used characteristic of heart rate is defined by the time interval between two heart beats and the number of beats per minute (see [52]). The variation of the heart beat intervals is called the heart rate variability (HRV). This parameter essentially expresses the rate at which the heart rate changes. It can be evaluated on the basis of various parameters. In this study the standard deviation of the R-wave intervals (SDNN) was used. Heart rate variability increases with fatigue (see [104]). The heart rate was measured using three disposable electrodes, which were attached according to the manufacturer's specifications of the Varioport measuring system. A derivation from the upper end of the breastbone to the left lowest ribcage is recommended. The ground electrode of the recorder is attached to the breast bone's xiphoid, which is located at the lower end of the breastbone. The data was collected at $500 \mathrm{~Hz}$ and recorded at $60 \mathrm{~Hz}$ synchronously with the vehicle data via the Silab 5.1 simulation software.

3.8.2.3 Blink frequency The lid closure was recorded with eye tracking glasses ETG2 from SMI. The evaluation was carried out with regard to the blink frequency. Stern et al. [90] and Platho et al. [75] proved that the blink frequency increases with increasing fatigue before rapidly decreasing shortly before falling asleep.

\subsubsection{Driving performance data}

Driving performance data were recorded directly via the Silab driving simulator software at $60 \mathrm{~Hz}$ and could then be analysed and averaged for all test persons. Driving performance data are divided into vehicle data and vigilance data and are described below.

3.8.3.1 Lane-keeping To evaluate the lane keeping, the standard deviation of the lateral position (SDLP) is evaluated. The lateral position is measured as the distance between the centre of the vehicle and the centre of the right-hand lane $[5,12,67]$.

Within the framework of our study, the lane position was calculated using the simulation software SILAB. Route sections with a curve or forced overtaking manoeuvres were excluded from the respective interval data (see chapter 3.8).

3.8.3.2 Incidents A frequently used method of performance validation is to consider incidents that have occurred. In general, an incident is considered to be an overstepping of the road mark due to unintentional manoeuvring $[23,94]$. In this study, an incident is assumed to have occurred when either the left or right lane markings are exceeded with the front and rear wheels. This corresponds to the definition of "crossing the road mark with only one side", which is frequently used in the literature [54].

3.8.3.3 Accidents Accidents are evaluated separately, as an extreme form of incidents. In this context, an accident is defined as the departure from the road to the right into the ditch or to the left across the lanes into the centre crash barrier.

3.8.3.4 Speed The speed was recorded in $\mathrm{km} / \mathrm{h}$ and the mean speed (MS) per interval (see chapter 3.9) was analysed to evaluate the driving performance. It was based on the assumption that average speed increases with increasing fatigue $[14,65]$. If sections with a speed limit 
deviating from $100 \mathrm{~km} / \mathrm{h}$ were located within the evaluation intervals (see chapter 3.9), these sections were excluded from the interval data, in order to consistently analyse the speed deviation from the $100 \mathrm{~km} / \mathrm{h}$ speed limit.

3.8.3.5 Vigilance Vigilance is the term used to describe the continuous attention paid to a stimulus-poor task and was first examined by Mackworth [56] using the clock-hand test. Today there is a large number of test designs that often require a test person to respond to a certain signal (cf. [48, 72, 87]). However, these tests interfere with the monotonous task to be investigated by imposing a secondary task. For this reason, we have decided to develop our own investigation method for vigilance assessment. The vigilance measurement is carried out using two indicators. On the one hand, various traffic signs were (de)placed on the $240 \mathrm{~km}$ long route. This means that there were three intensity levels in which the traffic signs were set up, unsuitable for the chosen driving scenario. The stages of intensity from which an ascending signal effect can be expected for the driver are as follows:

- Stage 1: Traffic sign known from national road traffic, but not to be found on motorways,

- Stage 2: Traffic sign shape/colouring known, but warning content not (e.g. moose danger in Germany),

- Stage 3: Traffic sign shape/colour unknown, content unknown (e.g. yellow warning sign for koalas in Germany).

One sign of each level was placed along the route for each driving scenario. After the test ride, the test persons had to identify the wrong signs from a list. They received a list of 12 signs, 9 of which did not appear during the test ride. While the vigilance measurement via the sign recognition rate was only carried out passively, i.e. was queried afterwards, a further test was implemented in the route, which actively checked the vigilance. At a distance of $232 \mathrm{~km}$ and a pre-set speed of $100 \mathrm{~km} / \mathrm{h}$, a wild boar was simulated running into the lane at a distance of $120 \mathrm{~m}$. The average reaction time of the test persons is used to record the vigilance. These reaction tests were also carried out by Steinberger et al. [89] and Neubauer et al. [66]. Both a brake pedal actuation and a steering manoeuvre are evaluated as a reaction.

\subsection{Data analysis}

For the data analysis, intervals were determined in which the driving tests were evaluated. The intervals where necessary in order to show the development of the measures over time and in order to have comparable sections between trials. As shown in Fig. 5, a total of nine interactions took place during the interaction ride. For each of these interaction sessions, a period of $5 \mathrm{mi}$ nutes or 10 kilometres was evaluated. In addition, $5 \mathrm{mi}$ nutes or 10 kilometres between the interactions were also evaluated in order to analyse the course of the parameters descriptively over time. This resulted in a total of 17 intervals with a starting point defined as a fixed waypoint. For the statistical comparisons between the driving scenarios, the total mean values over the entire driving time were calculated for each parameter, as well as the mean values for the second interaction interval (interval 3) and 3 further intervals every half hour (interval 7, interval 11 and interval 15). The evaluation started with interval 3 since interval 1 was necessary for habituation of the test person. The identical route-dependent intervals were evaluated for all three driving scenarios. The data were adjusted for outliers according to the Winsor method [18]. In addition to the $p$-value, the effect size (Cohen's d) was calculated for all statistical comparisons. The comparisons were carried out in a pair comparison between solo ride \& co-driver ride, interaction ride \& solo ride and interaction ride \& codriver ride using $\mathrm{t}$-tests for paired samples. In the case that no normal distribution of the data was given, the non-parametric Wilcoxon test was used.

\section{Results}

\subsection{Sample details}

The participants were distributed in almost equal proportions across the sexes. A total of 18 male (58.1\%) and 13 female $(41.9 \%)$ subjects took part in the experiment. The subjects were 20-60 years old and had an average age of about 30 years (M 30.45 years, SD 10.19), forming a rather young collective. In comparison, the average German professional driver is 39.8 years old [35]. The younger collective is reasoned by the fact that younger drivers in particular lose attention more quickly in monotonous driving situations [21], and by the fact that they are particularly frequently involved in fatigue-related accidents $[3,68,77,91]$. The average driving experience was approximately 13 years (M 13.29 years, SD 10.12).

\subsection{Subjective psycho-physiological data}

The results of the subjective psycho-physiological survey are shown in Table 3 and their comparisons are described below.

Subjective fatigue: Even if the test persons were instructed to appear in the same wakefulness state for all driving experiments, the fatigue levels were of course not always identical. For this reason, not the KSS values themselves were compared between the trials, but the differences between the fatigue levels before and after 


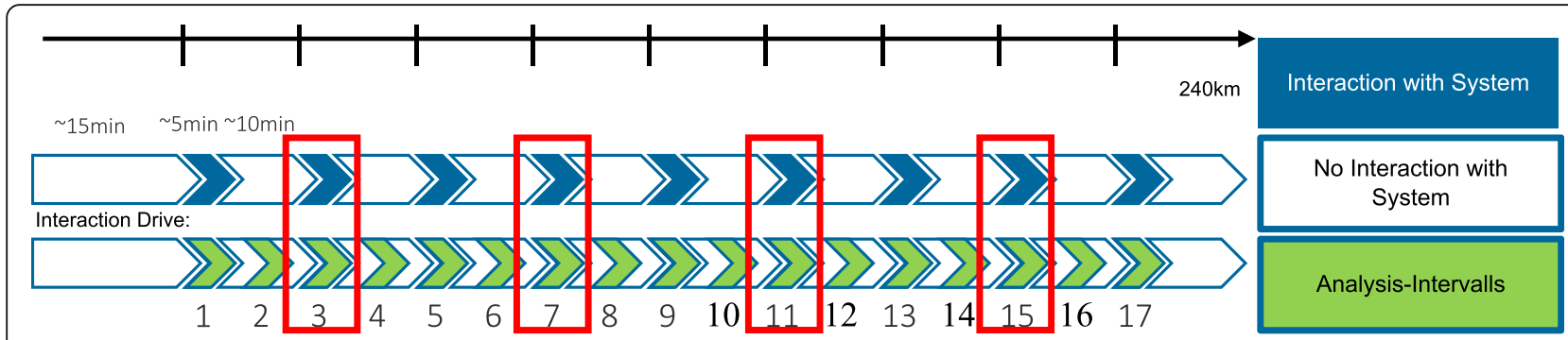

Fig. 5 Evaluation intervals of the measurement data

the trials. The differences thus describe the change in the state of fatigue over the course of the trial. A high positive difference represents a strong increase in the state of fatigue. The results show an average increase of 2.23 fatigue levels when driving alone and only 1.35 levels when interacting on the 9-step scale. The codriver ride even led to a reduction of the subjectively perceived fatigue by 0.35 steps. The differences between the scenarios were significant in all pair comparisons.

Subjective strain: The subjective strain was evaluated using the short form of the NASA TLX. The overall evaluation shows that the strain was highest during the interaction ride with 38.25 points out of 100 possible points. In contrast, the perceived strain of 36.83 points was only slightly lower for the solo ride. The perceived strain for the co-driver ride was 32.34 points. The only significant difference, with a small effect, is between the co-driver ride and the interaction ride. The higher overall score for solo driving results from a very high score for effort, which differs significantly from the score for effort in the other two scenarios. The high score of the interaction ride, on the other hand, results from a high evaluation of the mental requirement, which differs from the other rides with medium to strong effects.

\subsection{Objective psycho-physiological measurements}

The results of the analysis and comparisons of the objective psycho-physiological measurements are presented in Table 4 and explained below. Due to a system error, no reliable data were available for the ECG data for subject P8, who was subsequently excluded from the evaluation. During the recording of the blink frequency, the measuring system of the test persons P3, P4, P5, P9 and P28 was disturbed during one solo test ride each. In addition, the measurement system was not compatible with the head dimensions of P20, for which no data was available either.

Electrocardiography: Electrocardiography provided the standard deviation of the R-wave intervals (SDNN).

The SDNN is $66.36 \mathrm{~ms}$ for the solo ride, $72.02 \mathrm{~ms}$ for the co-driver ride and $65.42 \mathrm{~ms}$ for the interaction ride. When comparing the total values, there are no significant differences. In the interval analysis there is a significant difference with a slight effect between the interaction drive and the solo drive in interval 7 only. Here, the SDNN is $69.78 \mathrm{~ms}$ for solo rides and $64.11 \mathrm{~s}$ for interaction rides. The general development over the duration of the test ride (from interval 3 to interval 15) is comparable for all three rides with an increase in SDNN of about $15 \mathrm{~ms}$.

Blink frequency: The blink frequency was evaluated in form of an increase in relation to the first interval, since communication influences the blink frequency to a large extent and it therefore differs depending on the form of communication. The analysis of the increase in relation to the first interval with communication/interaction

Table 3 Results related to the subjective experience

\begin{tabular}{|c|c|c|c|c|c|c|c|c|c|c|c|}
\hline \multirow[t]{2}{*}{ Measure } & \multirow[t]{2}{*}{ Section } & \multicolumn{2}{|c|}{ Solo Ride (S) } & \multicolumn{2}{|c|}{ Co-Driver Ride $(C)$} & \multicolumn{2}{|c|}{ Interaction Ride (I) } & \multirow{2}{*}{$\begin{array}{l}\text { Stat. Test } \\
\mathrm{S}-1\end{array}$} & \multirow{2}{*}{$\begin{array}{l}\text { Effect } \\
S-I\end{array}$} & \multirow{2}{*}{$\begin{array}{l}\text { Stat. Test } \\
\mathrm{C}-\mathrm{I}\end{array}$} & \multirow{2}{*}{$\begin{array}{l}\text { Effect } \\
C-I\end{array}$} \\
\hline & & $M$ & SD & $\mathrm{M}$ & SD & $\mathrm{M}$ & SD & & & & \\
\hline KSS Difference & Pre- to Post-Trial & 2.23 & 2.01 & -0.35 & 1.98 & 1.35 & 1.58 & $\mathrm{t}=2.41^{* *}$ & $d=0.43$ & $\mathrm{t}=-3.84^{* * * *}$ & $d=0.69$ \\
\hline \multirow[t]{7}{*}{ NASA TLX } & Overall & 36.83 & 15.28 & 32.34 & 15.28 & 38.25 & 12.99 & $\mathrm{t}=-0.50$ & - & $t=-2.08^{* *}$ & $d=0.37$ \\
\hline & Mental Demand & 29.68 & 21.93 & 48.71 & 25.36 & 49.68 & 22.40 & $\mathrm{t}=-4.62^{* * * *}$ & $d=0.83$ & $t=-0.18$ & - \\
\hline & Physical Demand & 27.10 & 20.73 & 28.71 & 22.21 & 27.74 & 16.37 & $t=-0.16$ & - & $Z=-0.46$ & - \\
\hline & Temporal Demand & 20.81 & 14.77 & 25.00 & 16.42 & 29.52 & 14.85 & $\mathrm{t}=-2.95^{* * *}$ & $d=0.53$ & $t=-0.21$ & - \\
\hline & Performance & 40.81 & 25.43 & 29.84 & 20.51 & 38.71 & 16.02 & $t=212.5$ & - & $t=-2.36^{* *}$ & $d=42$ \\
\hline & Effort & 59.19 & 24.63 & 39.84 & 22.15 & 46.45 & 20.66 & $Z=-3.02^{* * *}$ & $d=0.53$ & $t=-1.54$ & - \\
\hline & Frustration & 43.39 & 26.47 & 23.87 & 20.68 & 37.42 & 20.97 & $Z=-1.50$ & - & $\mathrm{t}=-2.90^{* * *}$ & $d=0.52$ \\
\hline
\end{tabular}

${ }^{*} p<0.1$ low significance, ${ }^{* *} p<0.05$ significance, ${ }^{* * *} p<0.01$ strong significance, ${ }^{* * * *} p<0.001$ highest significance; Z: Wilcoxon signed-ranks test; t: paired samples t-test; 
Table 4 Results related to psycho-physiological arousal

\begin{tabular}{|c|c|c|c|c|c|c|c|c|c|c|c|}
\hline \multirow[t]{2}{*}{ Measure } & \multirow[t]{2}{*}{ Section } & \multicolumn{2}{|c|}{ Solo Ride (S) } & \multicolumn{2}{|c|}{ Co-Driver Ride (C) } & \multicolumn{2}{|c|}{ Interaction Ride (I) } & \multirow{2}{*}{$\begin{array}{l}\text { Stat. Test } \\
\mathrm{S}-\mathrm{I}\end{array}$} & \multirow{2}{*}{$\begin{array}{l}\text { Effect } \\
S-I\end{array}$} & \multirow{2}{*}{$\begin{array}{l}\text { Stat. Test } \\
\mathrm{C}-\mathbf{I}\end{array}$} & \multirow{2}{*}{$\begin{array}{l}\text { Effect } \\
C-I\end{array}$} \\
\hline & & $\bar{M}$ & SD & $\bar{M}$ & SD & $\bar{M}$ & SD & & & & \\
\hline \multirow[t]{5}{*}{ ECG (SDNN) [ms] } & Overall & 66.36 & 20.29 & 72.02 & 24.37 & 65.42 & 23.78 & $Z=-0.79$ & - & $Z=-0.96$ & - \\
\hline & Intervall 3 & 61.14 & 22.70 & 65.10 & 20.21 & 61.31 & 27.45 & $t=0.04$ & - & $Z=-1.59$ & - \\
\hline & Intervall 7 & 69.78 & 21.25 & 70.21 & 26.60 & 64.11 & 27.79 & $Z=-2.40^{* *}$ & $d=0.23$ & $Z=-0.83$ & - \\
\hline & Intervall 11 & 67.40 & 26.64 & 72.53 & 29.66 & 71.07 & 27.45 & $Z=-0.24$ & - & $t=-0.34$ & - \\
\hline & Intervall 15 & 74.37 & 31.06 & 77.54 & 26.77 & 72.99 & 25.48 & $\mathrm{t}=-0.32$ & - & $Z=-0.90$ & - \\
\hline \multirow[t]{5}{*}{ Increase Blinks [\%] } & Overall & 20.35 & 32.24 & 12.49 & 27.22 & 1.98 & 26.51 & $\mathrm{t}=-2.95^{* * *}$ & $d=0.57$ & $\mathrm{t}=-1.83^{*}$ & $d=0.36$ \\
\hline & Intervall 3 & 7.53 & 25.04 & 5.80 & 17.22 & -9.19 & 17.85 & $Z=-2.81^{* * *}$ & $d=0.58$ & $\mathrm{t}=-4.00^{* * * *}$ & $d=0.78$ \\
\hline & Intervall 7 & 32.76 & 44.18 & 14.37 & 31.35 & 10.32 & 30.13 & $t=-2.60^{* *}$ & $d=0.50$ & $Z=-1.41$ & - \\
\hline & Intervall 11 & 24.26 & 32.23 & 12.75 & 32.96 & -0.89 & 26.17 & $\mathrm{t}=-4.37^{* * * *}$ & $d=0.84$ & $t=-1.28$ & - \\
\hline & Intervall 15 & 17,22 & 46,72 & 23,16 & 44.84 & 4.76 & 21.54 & $\mathrm{t}=-1.22$ & - & $t=0.67$ & - \\
\hline \multirow[t]{5}{*}{$\mathrm{EDA}(\mathrm{SCL})[\mu \mathrm{S}]$} & Overall & 0.31 & 0.11 & 0.31 & 0.09 & 0.32 & 0.11 & $\mathrm{t}=0.39$ & - & $t=0.23$ & - \\
\hline & Intervall 3 & 0.25 & 0.14 & 0.34 & 0.16 & 0.35 & 0.16 & $\mathrm{t}=2.77^{* * *}$ & $d=0.50$ & $t=0.25$ & - \\
\hline & Intervall 7 & 0.32 & 0.17 & 0.29 & 0.13 & 0.35 & 0.16 & $\mathrm{t}=0.75$ & - & $\mathrm{t}=2.07^{* *}$ & $d=0.37$ \\
\hline & Intervall 11 & 0.34 & 0.17 & 0.28 & 0.14 & 0.33 & 0.15 & $t=-0.05$ & - & $t=1.64$ & - \\
\hline & Intervall 15 & 0.29 & 0.17 & 0.29 & 0.20 & 0.33 & 0.20 & $t=0.73$ & - & $t=0.66$ & - \\
\hline
\end{tabular}

${ }^{*} p<0.1$ low significance, ${ }^{* *} p<0.05$ significance, ${ }^{* * *} p<0.01$ strong significance, ${ }^{* * * *} p<0.001$ highest significance; Z: Wilcoxon signed-ranks test; t: paired samples t-test;

corresponds to this circumstance. The average increase of the blink frequency was $20.35 \%$ on the solo ride, $12.49 \%$ on the co-driver ride and only $1.98 \%$ on the interaction ride. Significant with a medium effect are the differences between solo and interaction test rides and with weak significance and slight effect between codriver and interaction test rides. The differences between solo and interaction driving increase over the course of the experiment and reach their maximum in interval 11. In contrast, no significant differences were observed in interval 15. Between co-driver ride and interaction ride there are significant differences at the beginning of the ride in interval 3 only.

Electrodermal activity: The SCL shows no differences between the mean values of the rides. The tonic value is $0.31 \mu \mathrm{S}$ for solo rides, $0.31 \mu \mathrm{S}$ for co-driver rides and $0.32 \mu \mathrm{S}$ for interaction rides. Over the course, significant differences occur in interval 3 with mean effects between co-driver and solo ride, as well as interaction and solo ride. Here, the SCL value of $0.25 \mu \mathrm{S}$ of the solo ride is significantly below the value of the interaction ride, $0.35 \mu \mathrm{S}$.

\subsection{Driving performance data}

The driving performance data are divided into the vehicle data and the vigilance data.

\subsubsection{Vehicle data}

The results of the analysis and comparison of the vehicle data are presented in Table 5 and explained below. For
P3 and P7 no data on steering movements are available as these were not recorded due to a system error.

Small steering movements: The amount of small steering movements with a steering angle of less than $5^{\circ}$ was $152.151 / \mathrm{km}$ on average for the co-driver ride and significantly higher with strong effects compared to 136.62 $1 / \mathrm{km}$ for the solo ride and $139.081 / \mathrm{km}$ for the interaction ride. The latter, on the other hand, show no significant differences. The effects of the significant differences are stable over all intervals, so that an identical course over time at different levels can be assumed.

4.4.1.1 SDLP The standard deviation of the lateral position was significantly higher with $0.32 \mathrm{~m}$ for solo driving and with strong effects compared to $0.28 \mathrm{~m}$ for the codriver driving and $0.29 \mathrm{~m}$ for interaction driving. The significant differences occur across all intervals. The SDLP drops to $0.22 \mathrm{~m}$ on the interaction ride in interval 3 and interval 11 and thus shows an overall minimum.

4.4.1.2 MS The average speed in the $100 \mathrm{~km} / \mathrm{h}$ restricted areas of the route is significantly lower on the interaction ride with $101.76 \mathrm{~km} / \mathrm{h}$ compared to $103.61 \mathrm{~km} / \mathrm{h}$ for the solo ride and $104.30 \mathrm{~km} / \mathrm{h}$ for the co-driver ride. There is also an overall significant difference between solo and co-driver rides. The significant differences occur between solo and interaction driving from the 7th interval onwards and persist until the 15th interval. The significant differences between co-driving and interactive driving exist across all intervals and have the strongest effects in interval 11. 
Table 5 Results related to driving performance

\begin{tabular}{|c|c|c|c|c|c|c|c|c|c|c|c|}
\hline \multirow[t]{2}{*}{ Measure } & \multirow[t]{2}{*}{ Section } & \multicolumn{2}{|c|}{ Solo Ride (S) } & \multicolumn{2}{|c|}{ Co-Driver Ride $(C)$} & \multicolumn{2}{|c|}{ Interaction Ride (I) } & \multirow{2}{*}{$\begin{array}{l}\text { Stat. Test } \\
S-1\end{array}$} & \multirow{2}{*}{$\begin{array}{l}\text { Effect } \\
S-I\end{array}$} & \multirow{2}{*}{$\begin{array}{l}\text { Stat. Test } \\
\mathrm{C}-1\end{array}$} & \multirow{2}{*}{$\begin{array}{l}\text { Effect } \\
C-I\end{array}$} \\
\hline & & $\mathrm{M}$ & SD & $\mathrm{M}$ & SD & $\bar{M}$ & SD & & & & \\
\hline$\overline{S D L P}$ & Overall & 0.32 & 0.05 & 0.28 & 0.04 & 0.29 & 0.05 & $Z=-4.154^{* * * *}$ & $d=0.94$ & $t=1.275$ & - \\
\hline \multirow[t]{4}{*}[\mathrm{m}]{} & Intervall 3 & 0.29 & 0.08 & 0.23 & 0.06 & 0.22 & 0.06 & $t=-5.197^{* * * *}$ & $d=0.93$ & $t=-1.293$ & - \\
\hline & Intervall 7 & 0.32 & 0.08 & 0.26 & 0.07 & 0.28 & 0.06 & $Z=-2.665^{* * *}$ & $d=0.53$ & $t=1.462$ & - \\
\hline & Intervall 11 & 0.31 & 0.07 & 0.27 & 0.06 & 0.22 & 0.09 & $Z=-3.841^{* * * *}$ & $d=0.82$ & $Z=-2.861^{* * *}$ & $d=0.05$ \\
\hline & Intervall 15 & 0.34 & 0.07 & 0.29 & 0.06 & 0.31 & 0.08 & $t=-1.981^{*}$ & $d=0.36$ & $t=1.540$ & - \\
\hline MS & Overall & 103.61 & 4.45 & 104.30 & 3.79 & 101.76 & 3.05 & $Z=-4.498^{* * * *}$ & $d=0.99$ & $Z=-4.505^{* * * *}$ & $d=1.07$ \\
\hline \multirow[t]{4}{*}[\mathrm{km}/\mathrm{h}]{} & Intervall 3 & 103.01 & 4.31 & 103.71 & 3.65 & 102.51 & 4.17 & $t=-1.208$ & - & $Z=-2.822^{* * *}$ & $d=0.44$ \\
\hline & Intervall 7 & 103.52 & 4.96 & 102.83 & 3.89 & 101.67 & 2.37 & $\mathrm{t}=-2.781^{* * *}$ & $d=0.50$ & $t=-2.424^{* *}$ & $d=0.44$ \\
\hline & Intervall 11 & 104.89 & 5.92 & 106.76 & 7.43 & 102.71 & 4.20 & $Z=-2.332^{* *}$ & $d=0.47$ & $Z=-2.979^{* * *}$ & $d=0.60$ \\
\hline & Intervall 15 & 103.96 & 5.98 & 104.18 & 5.86 & 102.25 & 2.93 & $Z=-2.047^{* *}$ & $d=0.45$ & $Z=-1.646^{*}$ & $d=0.40$ \\
\hline Incidents [n] & Overall & 54.84 & 32.57 & 38.74 & 33.04 & 42.84 & 31.79 & $t=3.205^{* * *}$ & $d=0.58$ & $-t=1.126$ & - \\
\hline Accidents [n] & Overall & 0.58 & 1.61 & 0.13 & 0.56 & 0.13 & 0.72 & $\mathrm{t}=-1.813^{*}$ & $d=0.33$ & $t=0.000$ & - \\
\hline
\end{tabular}

${ }^{*} p<0.1$ low significance, ${ }^{* *} p<0.05$ significance, ${ }^{* * *} p<0.01$ strong significance, ${ }^{* * * *} p<0.001$ highest significance; Z: Wilcoxon signed-ranks test; t: paired samples t-test;

The number of incidents: The number of incidents over the entire duration of the experiment was 54.84 incidents per test person on the solo ride, 38.74 incidents on the codriver ride and 42.84 incidents on the interaction ride. The differences between solo driving and co-driver respectively interaction driving are significant.

4.4.1.3 Accidents The number of accidents with the median crash barrier or the ditch was 0.58 accidents per test person on the solo ride and 0.13 accidents per test person on the co-driver and interaction ride. Due to the low overall number of accidents, the differences between the rides were only slightly significant. A total of 18 accidents occurred on the solo ride and 4 accidents on each of the other test rides.

\subsubsection{Vigilance}

The results of the analysis and comparisons of the vigilance data are presented in Table 6 and are explained below. For P9, no data on the reaction time and collision of the solo ride are available, as the simulator suffered a system crash shortly before the hazard situation.

4.4.2.1 Reaction time The reaction time to the wild boar, which entered the traffic lane $120 \mathrm{~m}$ ahead of the vehicle, was $1945 \mathrm{~ms}$ for the solo ride, $1822 \mathrm{~ms}$ for the co-driver ride and $2035 \mathrm{~ms}$ for the interaction ride. The differences between the rides were not significant.

4.4.2.2 Collisions A collision with the wild boar occurred in $30 \%$ of the trials when driving alone and with the co-driver, and in $37 \%$ of the trials when driving with the interaction. These differences were not statistically significant either.

4.4.2.3 Sign recognition Of the incorrectly placed signs, 2.42 out of 3 were recognized on the solo ride and only 2.03 out of 3 on the co-driver ride. On the interaction journey most signs were recognized with 2.84 out of 3 signs. The differences were significant with a slight effect between solo ride and interaction ride and highly significant with strong effects between co-driver ride and interaction ride.

\section{Discussion}

The results presented here are used at this point to answer the research questions presented at the beginning. Overall, the question arises as to whether the interaction system is a suitable way of avoiding fatigue caused by a

Table 6 Results related to vigilance

\begin{tabular}{|c|c|c|c|c|c|c|c|c|c|c|c|}
\hline \multirow[t]{2}{*}{ Measure } & \multirow[t]{2}{*}{ Section } & \multicolumn{2}{|c|}{ Solo Ride $(S)$} & \multicolumn{2}{|c|}{ Co-Driver Ride (C) } & \multicolumn{2}{|c|}{ Interaction Ride (I) } & \multirow{2}{*}{$\begin{array}{l}\text { Stat. Test } \\
S-1\end{array}$} & \multirow{2}{*}{$\begin{array}{l}\text { Effect } \\
S-I\end{array}$} & \multirow{2}{*}{$\begin{array}{l}\text { Stat. Test } \\
\mathrm{C}-\mathrm{I}\end{array}$} & \multirow{2}{*}{$\begin{array}{l}\text { Effect } \\
C-I\end{array}$} \\
\hline & & $\bar{M}$ & SD & $\bar{M}$ & SD & $\bar{M}$ & SD & & & & \\
\hline Reaction Time [ms] & Overall & 1945 & 642 & 1822 & 669 & 2035 & 567 & $t=0.68$ & - & $t=1.46$ & - \\
\hline Collisions & Overall & 0.30 & 0.47 & 0.30 & 0.53 & 0.37 & 0.49 & $\mathrm{t}=0.57$ & - & $\mathrm{t}=0.63$ & - \\
\hline Sign Recognition & Overall & 2.42 & 0.76 & 2.03 & 0.98 & 2.84 & 0.37 & $Z=-2.50^{* *}$ & $d=0.49$ & $Z=-3.62^{* * * *}$ & $d=0.80$ \\
\hline
\end{tabular}

${ }^{*} p<0.1$ low significance, ${ }^{* *} p<0.05$ significance, ${ }^{* * *} p<0.01$ strong significance, ${ }^{* * * *} p<0.001$ highest significance; Z: Wilcoxon signed-ranks test; t: paired samples t-test; 
monotonous driving situation. The reference is not only the solo ride, but also the ride with a co-driver.

\subsection{RQ1: how does the use of gamification in vehicle driving influence the development of subjective and objective psycho-physiological data and measurements compared to driving alone?}

An examination of the psycho-physiological parameters shows that the subjectively perceived fatigue increases significantly less when using the interaction system than when driving alone for the same driving time and distance. The test persons therefore feel less tired after the interaction ride than without the system.

The assumption that this was due to higher stress on the test person could not, however, be confirmed at first glance, since the evaluation of load using NASA TLX shows no significant differences. However, it can also be argued that the NASA TLX as an overall value is not sufficiently suitable to distinguish between underutilisation and overstrain. Galy et al. [27] have found similar results in a study and therefore suggest to consider the dimensions of the NASA TLX individually. This shows that the NASA score in solo driving is mainly caused by a high effort of the test persons, which differs significantly from the other test rides, although objectively the physical as well as mental effort is lowest. The stress therefore does not result from within the task but through the participant's effort to deal with being under-challenged.

The overall score of the interaction ride, on the other hand, results from a high rating of the mental requirement. This rating differs significantly from the other rides. As presumed, it is clear that the subjects are challenged to a greater extent by the interaction system. The lower subjective fatigue is therefore due to a less distinct under-utilisation.

The measurement methods used to collect psychophysiological data provide differing results. The mental strain is shown by ECG data on the SDNN. An increasing SDNN indicates higher fatigue [52]. However, the course of the SDNN and the overall average of the two test rides (solo and interaction) are largely identical. There was a significantly lower SDNN for the interaction ride in interval 7 only. It can be concluded that although the fatigue of the test persons reaches the same level over the entire driving time, the interaction system delays the occurrence of fatigue. Furthermore, it is possible that the used recording rate of $60 \mathrm{~Hz}$ is not sufficiently sensitive to detect further effects [49].

The increase of the blink frequency in relation to the first interval, on the other hand, shows clear effects of the interaction system. The blink frequency with a total increase of only $2 \%$ remains almost at its starting level. In comparison, the blink frequency increases by more than $20 \%$ on the solo ride, at times even by more than $30 \%$ (interval 7). Compared to the findings of McIntire et al. [61], this shows that the monotonous fatigue of the eyes and thus a decrease in vigilance can be avoided by using the interaction system through the presentation of new stimuli.

The SCL is not able to support this hypothesis at first sight, since the level of SCL in the investigated intervals was almost identical for both test rides. However, a look at the entire course (see Fig. 6) provides further information. There could be a superposition of influences on the SCL. Since the values for the solo rides increase steadily, an increase in fatigue can be deduced due to the absence of further influences on the SCL. During the interaction rides, however, the SCL starts at a higher level with continuous ascents and descents over time. A higher skin conductivity can be observed in all interaction intervals. This is obviously due to the excitement or tension of the subject during the interactions $[15,31]$. Subsequently, however, SCL dropped back to a significantly lower level. Nevertheless, no significance could be found for the differences. In combination with the clear results of the blink frequency it can be concluded that the SCL is only conditionally suitable as a measured quantity due to the superimposition effects.

In summary, the results of the different tests are contradicting and don't give clear enough information to answer the research question in detail.

\subsection{RQ2: how does the use of gamification in vehicle driving influence driving performance and safety compared to driving alone?}

The standard deviation of the lateral position provides information about the quality of the lateral control. With the SDLP there are significant differences between the rides, whereby the SDLP of the interaction ride is lower with strong effects than that of the solo ride. The test persons were therefore able to significantly improve their driving performance in terms of lateral guidance by using the interaction system. It should be noted that that the effect has decreased significantly in interval 15, causing the SDLP to gradually align. This suggests that even when using the interaction system, the driving task should be gradually interrupted after $2.5 \mathrm{~h}$.

The number of incidents reflects the extent to which the steady increase in SDLP can result in dangerous driving situations. On average the test persons left their own lane with front and rear wheels almost 55 times for no reason when driving alone. During the interaction ride, however, such incidents occurred only 33 times. Leaving one's own lane may be due to the fact that the test person tries to entertain himself with dangerous manoeuvres $[85,89]$, or to the fact that such manoeuvres may also be caused by fatigue-related inattention. The 


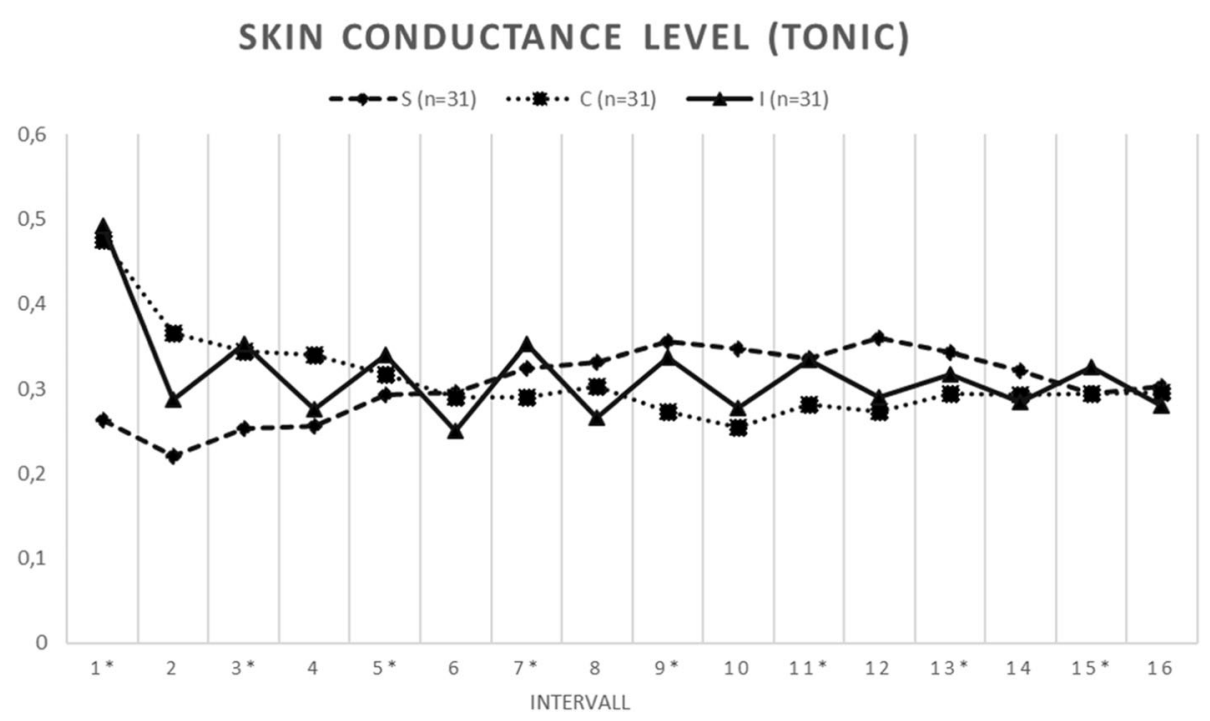

Fig. 6 Trend of tonic skin conductance across all intervals

fact that a total of 18 accidents with the centre crash barrier or the side ditch were caused by all test persons during the solo ride shows the drastic extent of such incidents. During the interaction ride this risk could be clearly reduced by the system introduction and thus the driving safety could be increased. Here only 4 accidents occurred.

Another important aspect of driving performance is the longitudinal guidance, which can be measured qualitatively, for example, in compliance with speed limits. For this purpose, we have evaluated the average speed driven in $100 \mathrm{~km} / \mathrm{h}$ zones. There is a significant difference with strong effects between solo driving and interaction driving. It is clear that the interaction system contributes to a safer driving style. In addition, the mean values of the speed driven are stable during interaction driving, while they increase steadily during solo driving.

The vigilance of the test persons was considered and evaluated as a further component of the driving performance. Here the reaction test might have occurred too late to gain any information from the test. This conclusion can be traced back to the fact that the reaction times to the hazard at the end of the driving test were, with just under $2 \mathrm{~s}$, significantly higher in all driving scenarios than in attentive drivers. The literature suggests reaction times of $1.2-1.4 \mathrm{~s}[88,106]$. Since braking was computationally possible in relation to the speed driven, the frequency with which a collision with the wild boar occurred was too high. For all tests, this frequency varied from $30 \%$ to $37 \%$ and did not differ significantly between the groups.

The sign recognition, on the other hand, shows that the test persons were more vigilant for the driving task due to the interaction system, because significantly more signs were recognized compared to driving alone. Awareness of the vehicle environment and of current traffic regulations is an important part of the driving task [24]. This once again shows that the interaction system increases driving safety.

In summary, the research question can be answered as follows. The interaction system significantly improves the driving performance of the test persons compared to solo driving and contributes to an increase in vigilance and thus overall driving safety.

\subsection{RQ3: is the interaction system suitable for avoiding fatigue in the same way as a passenger during monotonous journeys?}

The last research question can only be answered by a renewed consideration of all measured variables. Psychophysiological parameters, e.g. the assessment of subjective fatigue with the KSS, showed a difference in favour of the co-driver. Even tendencies which could not be proven to be significant by comparison tests indicate for SCL that the passenger interaction is slightly superior to the interaction system with regard to fatigue avoidance. The increases in the blink frequency, on the other hand, are significantly greater for the co-driver ride, indicating higher fatigue.

The driving performance data indicate that although the test persons performed more small steering movements during the entire ride, which at first suggests an attentive driving style $[54,93]$, the quality measured by the SDLP shows a significant difference between the rides only in interval 11 . This difference, in turn, speaks in favour of significantly better lateral guidance during the interaction journey in interval 11. Compliance with the speed limit worked best during the interaction ride 
and showed the greatest violations during the co-driver ride. The number of incidents and accidents, on the other hand, showed no differences.

The vigilance measured through the reaction time and the collisions during hazard was identical. However, the sign recognition was weakest during the codriver ride. It can therefore be concluded that, according to the study, fatigue can be avoided with comparable success when driving with the interaction system and when driving with co-drivers. However, distractions from conversations with the co-driver tended to have a negative effect on driving performance. The topics of conversation during the passenger ride did not offer any potential for conflict and the co-drivers were also urged not to engage in any disputes in order not to influence the trials. Nevertheless, disputes with the co-driver can have a considerable influence on driving safety [99].

\subsection{Limitations}

Every study has certain limitations that must be taken into account when interpreting the results. Due to the composition of our study, the results reflect the opinion and performance of young adults. Consequently, we cannot generalize our findings to drivers of all ages. However, young drivers are likely to be an important user group of applications for safe driving. The heterogeneity of the examined sample in relation to driving practice also limits the generalizability of the findings, since driving behaviour is experience-related [60]. Similarly, previous experience with driving simulators and computer games may have affected the participants' performance.

Due to the partial need to use the non-parametric Wilcoxon test, which has less ability to detect significance than parametric tests, quantitative results were often not statistically recorded. A larger sample size would be required to determine the significance of the results. However, our sample size was similar to related studies [81] and sufficient to show effect sizes.

In order to finally ensure that the distraction by the system does not represent a safety-critical risk, the gaze distribution should be examined in further studies. Further a larger number of hazards should be integrated into the examination concept in order to analyse the reaction times in more detail.

However, in order to achieve the most monotonous route possible, the present study avoided those hazards.

The lack of significant differences in SDNN may have been caused by the controlled laboratory environment. Specifically, the interaction system required a darkened room for optimal visual representation in the head-up display. The driving simulator is also known to cause lower excitation values by reducing the ambient light [73].

\section{Conclusion}

In a simulator study, we investigated the safety-critical effects of monotony in vehicle driving. Digital technologies and the approach of gamification, which has so far been unused, offer the possibility of permanently integrating the driver into the driving task and thus increasing safety. This paper presents empirical data that investigate the effects of a gamification concept and contribute to a better understanding of monotony and its effects on driving performance.

The investigated intervention contributed to a significant reduction in speed and thus promotes safe driving. We also found effects that speak for increased attention to the primary driving task, which is reflected both in the driver behaviour data (improved lateral control) and in the physiological data (decreased fatigue signs of visual sensory modality). We can further deduce that the intervention has not only increased attention and excitement during the use of the interaction system, but also in between. This is indicated by the improved perception of street signs, which are part of the driving task. This could also be derived from trends in SCL, but could not be confirmed significantly.

The stimuli presented by gamification can thus help to maintain attention and excitement during a journey. In comparison to stimuli caused by communication with a co-driver, the stimuli provided by gamification are directed towards the driving task itself. Therefore, the driving task becomes more attractive for the drivers again. This approach ensures that the distraction from the primary task is kept to a minimum. These findings reflect results from Markey et al. [58] and Steinberger et al. [89], whose experiments have shown that engagement in repetitive computer-based tasks can be increased through additional challenges, performance feedback and rewards.

Future research studies should focus on improving interval distances between incipient interactions. A follow-up survey of the test persons showed that the intervals of 10 min between two interactions were too long and the objective data also suggest this in parts. Overall, however, the interaction system was very positively received by the test.

Implementation of the interaction concept in practice must ensure that the use of interactions is prevented or interrupted in critical traffic situations. For this purpose, the interaction system must be connected to the vehicle's environmental sensors. Since all results have been obtained in a driving simulator, this study must be repeated in real traffic before such an interaction system can be used in practice.

\section{Abbreviations}

ECG: Electrocardiogram; EDA: Electrodermal Activity; HRV: Heart Rate Variability; HUD: Head up Display; KSS: Karolinska Sleepiness Scale; M: Mean Value; MS: Mean Speed; NASA TLX: NASA Task Load Index; SCL: Skin 
Conductance Level; SD: Standard Deviation; SDLP: Standard Deviation of the Lateral Position; SDNN: Standard Deviation of the R-wave Intervals; $\mu S$ : Micro Siemens

\section{Acknowledgements}

Not applicable.

\section{Authors' contributions}

$B L$ was leading the research team on "gamification as intervention of fatigue caused by monotony". He wrote the article by himself with the data provided by following authors. EM wrote his bachelor thesis in the research team about blink frequency and analyzed mentioned data. He also supervised parts of the simulator study. GK wrote her master thesis in the research team about acceptance of the gamification system and analyzed mentioned data. She also supervised parts of the simulator study. KJ wrote her student research thesis in the research team about lateral control and analyzed mentioned data. She also supervised parts of the simulator study. $\mathrm{RD}$ wrote his bachelor thesis in the research team about longitudinal control and analyzed mentioned data. He also supervised parts of the simulator study. PM wrote his student research thesis in the research team about monotone track design and implemented the track into the simulator. $A B$ is the deputy director of the institute and has proofread the article and advised on changes. She is now the corresponding author. All authors read and approved the final manuscript.

\section{Funding}

This research project was financially supported by the German Social Accident Insurance Institution for Commercial Transport, Postal Logistics and Telecommunication (BG Verkehr). The authors are fully responsible for the content of this study and publication. We further acknowledge support by the German Research Foundation and the Open Access Publishing Fund of Technische Universität Darmstadt.

\section{Availability of data and materials}

The datasets used and/or analysed during the current study are available from the corresponding author on reasonable request.

\section{Competing interests}

The authors declare that they have no competing interests.

\section{Received: 3 July 2019 Accepted: 4 October 2019}

\section{Published online: 29 October 2019}

\section{References}

1. Åkerstedt, T., \& Gillberg, M. (1990). Subjective and objective sleepiness in the active individual. The International Journal of Neuroscience, 52(1-2), 29-37. https://doi.org/10.3109/00207459008994241.

2. Åkerstedt, T., Peters, B., Anund, A., \& Kecklund, G. (2005). Impaired alertness and performance driving home from the night shift: A driving simulator study. Journal of Sleep Research, 14(1), 17-20. https://doi.org/10.1111/j.13652869.2004.00437.x.

3. Al-Houqani, M., Eid, H. O., \& Abu-Zidan, F. M. (2013). Sleep-related collisions in United Arab Emirates. Accident; Analysis and Prevention, 50, 1052-1055. https://doi.org/10.1016/j.aap.2012.08.010.

4. Anund, A., Kecklund, G., Vadeby, A., Hjälmdahl, M., \& Akerstedt, T. (2008). The alerting effect of hitting a rumble strip-A simulator study with sleepy drivers. Accident; Analysis and Prevention, 40(6), 1970-1976. https://doi.org/ 10.1016/j.aap.2008.08.017.

5. Arnedt, J. T., Wilde, G. J. S., Munt, P. W. \& MacLean, A. W. (2001). How do prolonged wakefulness and alcohol compare in the decrements they produce on a simulated driving task? Accident; Analysis and Prevention, 33(3), 337-344. https://doi.org/10.1016/S0001-4575(00)00047-6.

6. Atchley, P., Chan, M., \& Gregersen, S. (2014). A strategically timed verbal task improves performance and neurophysiological alertness during fatiguing drives. Human Factors: the Journal of the Human Factors and Ergonomics Society, 56(3), 453-462. https://doi.org/10.1177/0018720813500305.

7. Bach, W. E., \& Müller, H. A. (1981). Beifahrer und Mitfahrer im Straßenverkehr - Risikofaktoren oder Sicherheitsfaktoren?: Eine Diskussion auf gruppentheoretischer basis. Zeitschrift Für Verkehrssicherheit, 27(2), 60-64.

8. Becker-Carus, C. (2009). Ermüdung. In H. Häcker, K. H. Stapf, C. Becker-Carus, \& F. Dorsch (Eds.), Dorsch Psychologisches Wörterbuch: [15000 Stichwörter, 800
Testnachweise] hrsg. von Hartmut O. Häcker; Kurt-H. Stapf. Unter ständiger Mitarb. von Christian Becker-Carus (pp. 281-282). Bern: Huber.

9. Bier, L., Negash, S., \& Pommeranz, T. (2018). Preventing monotony caused fatigue with driver-vehicle-interaction - A design concept. In Arbeit(s). Wissenschaf(ff)t - Grundlage für Management \& Kompetenzentwicklung: 64. Kongress der Gesellschaft für Arbeitswissenschaft : Frankfurt, 21.-23. Februar 2018 (B.4.2). Dortmund: GfA-Press.

10. Bier, L., Wolf, P., Hilsenbek, H., \& Abendroth, B. (2018). How to measure monotony-related fatigue? A systematic review of fatigue measurement methods for use on driving tests. Theoretical Issues in Ergonomics Science, 52(1), 1-38. https://doi.org/10.1080/1463922X.2018.1529204.

11. Boucsein, W. (1988). Elektrodermale Aktivität: Grundlagen, Methoden und Anwendungen. Berlin: SpringerRetrieved from. https://doi.org/10.1007/978-3662-06968-4.

12. Boyle, L. N., Tippin, J., Paul, A., \& Rizzo, M. (2008). Driver performance in the moments surrounding a microsleep. Transportation Research Part F, 11(2), 126-136. https://doi.org/10.1016/j.trf.2007.08.001.

13. Brooks, J. O., Goodenough, R. R., Crisler, M. C., Klein, N. D., Alley, R. L., Koon, B. L., et al. (2010). Simulator sickness during driving simulation studies. Accident: Analysis and Prevention, 42(3), 788-796. https://doi.org/10.1016/j.aap.2009.04.013.

14. Campagne, A., Pebayle, T., \& Muzet, A. (2004). Correlation between driving errors and vigilance level: Influence of the driver's age. Physiology \& Behavior, 80(4), 515-524. https://doi.org/10.1016/j.physbeh.2003.10.004.

15. Carter, J. R., Durocher, J. J., \& Kern, R. P. (2008). Neural and cardiovascular responses to emotional stress in humans. American Journal of Physiology. Regulatory, Integrative and Comparative Physiology, 295(6), R1898-R1903. https://doi.org/10.1152/ajpregu.90646.2008.

16. Cooper, M. D. (2000). Towards a model of safety culture. Safety Science, 36(2), 111-136. https://doi.org/10.1016/S0925-7535(00)00035-7

17. Deterding, S., Dixon, D., Khaled, R., \& Nacke, L. (2011). From game design elements to gamefulness. In A. Lugmayr, H. Franssila, C. Safran, \& I. Hammouda (Eds.), Proceedings of the 15th International Academic MindTrek conference on envisioning future media environments-MindTrek, 11 (p. 9). New York: ACM Press. https://doi.org/10.1145/2181037.2181040.

18. Dixon, W. J., \& Yuen, K. K. (1974). Trimming and winsorization: A review. Statistische Hefte, 15(2-3), 157-170. https://doi.org/10.1007/BF02922904.

19. Doherty, Andrey, \& Gregor. (1998). The situational risks of young drivers: The influence of passengers, time of day and day of week on accident rates. In B. V. Elsevier (Ed.), Accident analysis and prevention (pp. 45-52). Philadelphia: Elsevier B.V.

20. Drews, F. A., Pasupathi, M., \& Strayer, D. L. (2008). Passenger and cell phone conversations in simulated driving. American Psychological Association ( $\mathrm{Hg})$ 2008 - Journal Of Experimental Psychology, 14(4), 392-400. https://doi.org/10. 1037/a0013119.

21. Drory, A. (1982). Individual differences in boredom proneness and task effectiveness at work. Personnel Psychology, 35(1), 141-151. https://doi.org/ 10.1111/j.1744-6570.1982.tb02190.x.

22. Eoh, H. J., Chung, M. K., \& Kim, S.-H. (2005). Electroencephalographic study of drowsiness in simulated driving with sleep deprivation. International Journal of Industrial Ergonomics, 35(4), 307-320. https://doi.org/10.1016/j. ergon.2004.09.006.

23. Fairclough, S. H., \& Graham, R. (1999). Impairment of driving performance caused by sleep deprivation or alcohol: A comparative study. Human Factors: the Journal of the Human Factors and Ergonomics Society, 41(1), 118 128. https://doi.org/10.1518/001872099779577336.

24. Fastenmeier, W., \& Gstalter, H. (2007). Driving task analysis as a tool in traffic safety research and practice. Safety Science, 45(9), 952-979. https://doi.org/ 10.1016/j.ssci.2006.08.023.

25. Fletcher, L., Petersson, L., \& Zelinsky, A. (2005). Road scene monotony detection in a fatigue management driver assistance system. In Intelligent vehicles symposium (pp. 484-489). https://doi.org/10.1109/IVS.2005.1505150.

26. Forsman, P. M., Vila, B. J., Short, R. A., Mott, C. G., \& van Dongen, H. P. A. (2013). Efficient driver drowsiness detection at moderate levels of drowsiness. Accident; Analysis and Prevention, 50, 341-350. https://doi.org/10. 1016/j.aap.2012.05.005.

27. Galy, E., Paxion, J., \& Berthelon, C. (2018). Measuring mental workload with the NASA-TLX needs to examine each dimension rather than relying on the global score: An example with driving. Ergonomics, 61(4), 517-527. https:// doi.org/10.1080/00140139.2017.1369583.

28. Gastaldi, M., Rossi, R., \& Gecchele, G. (2014). Effects of driver task-related fatigue on driving performance. Procedia - Social and Behavioral Sciences, 111, 955-964. https://doi.org/10.1016/j.sbspro.2014.01.130. 
29. Gershon, P., Shinar, D., \& Ronen, A. (2009). Evaluation of experience-based fatigue countermeasures. Accident; Analysis and Prevention, 41(5), 969-975. https://doi.org/10.1016/j.aap.2009.05.012.

30. Giesa. (2003). NASA task load index.

31. Gimeno, P. T., Cerezuela, G. P., \& Montanes, M. C. (2006). On the concept and measurement of driver drowsiness, fatigue and inattention: Implications for countermeasures. International Journal of Vehicle Design, 42(1/2), 67. https://doi.org/10.1504/IJVD.2006.010178.

32. Greschner, U. (2011). Experimentelle Untersuchung von Maßnahmen gegen Schläfrigkeit beim Führen von Kraftfahrzeugen (p. 511). https://doi.org/10. 18419/opus-4441.

33. Grier, R. A. (2015). How high is high? A meta-analysis of NASA-TLX global workload scores. Proceedings of the Human Factors and Ergonomics Society Annual Meeting, 59(1), 1727-1731. https://doi.org/10.1177/1541931215591373.

34. Hamari, J., Koivisto, J., \& Sarsa, H. (2014). Does Gamification Work? - A Literature Review of Empirical Studies on Gamification. In proceedings of the 47th Hawaii International Conference on System Sciences, Hawaii, USA, January 6-9, 2014

35. Handelsblatt. (2012). Altersstruktur von deutschen Berufskraftfahrern im Jahr 2012. Statista - Das Statistik-Portal Retrieved from https://de.statista.com/ statistik/daten/studie/242618/umfrage/altersstruktur-von-berufskraftfahrern/.

36. Hart, S. G., \& Staveland, L. E. (1988). Development of NASA-TLX (task load index): Results of empirical and theoretical research. In P. A. Hancock \& N. Meshkati (Eds.), Advances in psychology: v. 52. Human mental workload (Vol. 52, 1st ed., pp. 139-183S.I.: Elsevier textbooks). https://doi.org/10.1016/ S0166-4115(08)62386-9.

37. Hayami, T., Matsunaga, K., Shidoji, K., \& Matsuki, Y. (2002). Detecting drowsiness while driving by measuring eye movement- a pilot study. In Intelligent transportation systems. Advance online publication. https://doi. org/10.1109/ITSC.2002.1041206

38. Hoddes, E., Dement, W. C., \& Zarcone, V. (1972). Stanford-sleepiness-scale.

39. Horne, J. A., \& Reyner, L. A. (2001a). Beneficial effects of an "energy drink" given to sleepy drivers. Amino Acids, 20(1), 83-89. https://doi.org/10.1007/ s007260170068

40. Horne, J. A., \& Baulk, S. D. (2004). Awareness of sleepiness when driving. Psychophysiology, 41(1), 161-165. https://doi.org/10.1046/j.1469-8986.2003. 00130.x.

41. Horne, J., \& Reyner, L. (2001b). Sleep-related vehicle accidents: Some guides for road safety policies. Transportation Research Part F: Traffic Psychology and Behaviour, 4(1), 63-74.

42. Ingham, R. (1991). The effects of age, sex, time pressure and passengers on self-reported driving violations. In International conference on traffic safety, proceedings (pp. 248-251).

43. Ingre, M., Akerstedt, T., Peters, B., Anund, A., \& Kecklund, G. (2006). Subjective sleepiness, simulated driving performance and blink duration: Examining individual differences. Journal of Sleep Research, 15(1), 47-53. https://doi.org/ 10.1111/j.1365-2869.2006.00504.x

44. ISO 10075-2:1996. (1996). Ergonomic principles related to mental workload-Part 2: Design principles ISO/TC 159/SC 1.

45. Johns, M. W. (1991). A new method for measuring daytime sleepiness: The Epworth sleepiness scale. Sleep, 14(6), 540-545.

46. Karrer-Gauß, K. (2011). Ableitung von Gestaltungsempfehlungen zur Vermeidung von Risikokompensation aus empirischen Untersuchungen

47. Klarkowski, M., Johnson, D., Wyeth, P., McEwan, M., Phillips, C., \& Smith, S. (2016). Operationalising and evaluating sub-optimal and optimal play experiences through challenge-skill manipulation. In J. Kaye, A. Druin, C. Lampe, D. Morris, \& J. P. Hourcade (Eds.), \#chi4good: CHI 2016 : San Jose, CA, USA, May 7-12: Proceedings: The 34th annual CHI conference on human factors in computing systems : San Jose convention center (pp. 5583-5594). New York: The Association for Computing Machinery. https://doi.org/10. $1145 / 2858036.2858563$

48. Körber, M., Cingel, A., Zimmermann, M., \& Bengler, K. (2015). Vigilance decrement and passive fatigue caused by monotony in automated driving. Procedia Manufacturing, 3, 2403-2409. https://doi.org/10.1016/j.promfg.2015.07.499.

49. Laborde, S., Mosley, E., \& Thayer, J. F. (2017). Heart rate variability and cardiac vagal tone in psychophysiological research - Recommendations for experiment planning, data analysis, and data reporting. Frontiers in Psychology, 8. https://doi.org/10.3389/fpsyg.2017.00213.

50. Lal, S. K. L., \& Craig, A. (2001). A critical review of the psychophysiology of driver fatigue. Biological Psychology, 55(3), 173-194. https://doi.org/10.1016/ S0301-0511(00)00085-5.
51. Langer, I., Abendroth, B., \& Bruder, R. (2012). Fahrerzustandserkennung. In H. Winner, S. Hakuli, F. Lotz, \& C. Singer (Eds.), ATZ. Handbuch

Fahrerassistenzsysteme: Grundlagen, Komponenten und Systeme für aktive Sicherheit und Komfort (pp. 687-699). Wiesbaden: Vieweg+Teubner Verlag; Wiesbaden : Imprint: Springer Vieweg.

52. Larue, G. S., Rakotonirainy, A., \& Pettitt, A. N. (2011). Driving performance impairments due to hypovigilance on monotonous roads. Accident; Analysis and Prevention, 43(6), 2037-2046. https://doi.org/10.1016/j.aap.2011.05.023.

53. Lenné, M. G., Triggs, T. J., \& Redman, J. R. (1997). Time of day variations in driving performance. Accident; Analysis and Prevention, 29(4), 431-437. https://doi.org/10.1016/S0001-4575(97)00022-5.

54. Liu, C. C., Hosking, S. G., \& Lenné, M. G. (2009). Predicting driver drowsiness using vehicle measures: Recent insights and future challenges. Journal of Safety Research, 40(4), 239-245. https://doi.org/10.1016/j.jsr.2009.04.005.

55. Liu, S. (2015). An experimental study of driver fatigue: Subjective driver fatigue score, driving performance, and driver fatigue countermeasures (dissertation). Hamilton: McMaster University.

56. Mackworth, N. H. (1948). The breakdown of vigilance during prolonged visual search. The Quarterly Journal of Experimental Psychology, 1(1), 6-21. https://doi.org/10.1080/17470214808416738.

57. MacLean, A. W., Davies, D. R. T., \& Thiele, K. (2003). The hazards and prevention of driving while sleepy. Sleep Medicine Reviews, 7(6), 507-521. https://doi.org/10.1016/\$1087-0792(03)90004-9.

58. Markey, A., Chin, A., Vanepps, E. M., \& Loewenstein, G. (2014). Identifying a reliable boredom induction. Perceptual and Motor Skills, 119(1), 237-253. https://doi.org/10.2466/27.PMS.119c18z6.

59. May, J. F., \& Baldwin, C. L. (2009). Driver fatigue: The importance of identifying causal factors of fatigue when considering detection and countermeasure technologies. Transportation Research Part F: Traffic Psychology and Behaviour, 12(3), 218-224. https://doi.org/10.1016/j.trf.2008.11.005.

60. McCartt, A. T., Shabanova, V. I., \& Leaf, W. A. (2003). Driving experience, crashes and traffic citations of teenage beginning drivers. Accident; Analysis and Prevention, 35(3), 311-320. https://doi.org/10.1016/S0001-4575(02)00006-4.

61. McIntire, L. K., McKinley, R. A., Goodyear, C., \& McIntire, J. P. (2014). Detection of vigilance performance using eye blinks. Applied Ergonomics, 45(2), 354362. https://doi.org/10.1016/..apergo.2013.04.020.

62. Merat, N., \& Jamson, A. H. (2013). The effect of three low-cost engineering treatments on driver fatigue: A driving simulator study. Accident; Analysis and Prevention, 50, 8-15. https://doi.org/10.1016/j.aap.2012.09.017.

63. Mets, M. A. J., Ketzer, S., Blom, C., van Gerven, M. H., van Willigenburg, G. M., Olivier, B., \& Verster, J. C. (2011). Positive effects of red bull ${ }^{\circledR}$ energy drink on driving performance during prolonged driving. Psychopharmacology, 214(3), 737-745. https://doi.org/10.1007/s00213-010-2078-2.

64. Moller, H. J., Kayumov, L., Bulmash, E. L., Nhan, J., \& Shapiro, C. M. (2006) Simulator performance, microsleep episodes, and subjective sleepiness: Normative data using convergent methodologies to assess driver drowsiness. Journal of Psychosomatic Research, 61(3), 335-342. https://doi. org/10.1016/j.jpsychores.2006.04.007.

65. Morales, J. M., Díaz-Piedra, C., Rieiro, H., Roca-González, J., Romero, S., Catena, A., et al. (2017). Monitoring driver fatigue using a single-channel electroencephalographic device: A validation study by gaze-based, driving performance, and subjective data. Accident; Analysis and Prevention, 109, 6269. https://doi.org/10.1016/.aap.2017.09.025

66. Neubauer, C., Matthews, G., \& Saxby, D. (2014). Fatigue in the automated vehicle: Do games and conversation distract or energize the driver? Proceedings of the Human Factors and Ergonomics Society Annual Meeting, 58(1), 2053-2057. https://doi.org/10.1177/1541931214581432.

67. Otmani, S., Pebayle, T., Roge, J., \& Muzet, A. (2005). Effect of driving duration and partial sleep deprivation on subsequent alertness and performance of car drivers. Physiology \& Behavior, 84(5), 715-724. https://doi.org/10.1016/j. physbeh.2005.02.021.

68. Pack, A. I., Pack, A. M., Rodgman, E., Cucchiara, A., Dinges, D. F., \& Schwab, C. W. (1995). Characteristics of crashes attributed to the driver having fallen asleep. Accident; Analysis and Prevention, 27(6), 769-775. https://doi.org/10. 1016/0001-4575(95)00034-8.

69. Patel, M., Lal, S. K. L., Kavanagh, D., \& Rossiter, P. (2011). Applying neural network analysis on heart rate variability data to assess driver fatigue. Expert Systems with Applications, 38(6), 7235-7242. https://doi.org/10.1016/j.eswa. 2010.12.028

70. Pattyn, N., Neyt, X., Henderickx, D., \& Soetens, E. (2008). Psychophysiological investigation of vigilance decrement: Boredom or cognitive fatigue? 
Physiology \& Behavior, 93(1-2), 369-378. https://doi.org/10.1016/.jphysbeh. 2007.09.016.

71. Paul, A., Boyle, L. N., Tippin, J., \& Rizzo, M. (2005). Variability of driving performance during microsleeps. In Proceedings of the third international driving symposium on human factors in driver assessment, training and vehicle design (pp. 18-24). https://doi.org/10.17077/drivingassessment.1138.

72. Philip, P., Sagaspe, P., Moore, N., Taillard, J., Charles, A., Guilleminault, C., \& Bioulac, B. (2005). Fatigue, sleep restriction and driving performance. Accident; Analysis and Prevention, 37(3), 473-478. https://doi.org/10.1016/j. aap.2004.07.007.

73. Philip, P., Sagaspe, P., Taillard, J., Valtat, C., Moore, N., Akerstedt, T., et al. (2005). Fatigue, sleepiness, and performance in simulated versus real driving conditions. Sleep, 28(12), 1511-1516. https://doi.org/10.1093/sleep/28.12.1511.

74. Piotrowski, Z., \& Szypulska, M. (2017). Classification of falling asleep states using HRV analysis. Biocybernetics and Biomedical Engineering, 37(2), 290-301. https://doi.org/10.1016/j.bbe.2017.02.003.

75. Platho, C., Pietrek, A., \& Kolrep, H. (2013). Erfassung der Fahrermüdigkeit. Berichte der Bundesanstalt für Strassenwesen : F, Fahrzeugtechnik: Vol. 89. Bremen: Schünemann.

76. Popp, R. F. J. (2006). Gegenmaßnahmen bei Schläfrigkeit: Der Effekt von kurzwelligem Licht und olfaktorischer stimulation. (dissertation). Regensburg: Universität Regensburg Retrieved from https:/epub.uni-regensburg.de/10381/.

77. Radun, I., \& Radun, J. E. (2009). Convicted of fatigued driving: Who, why and how? Accident; Analysis and Prevention, 41(4), 869-875. https://doi.org/10. 1016/j.aap.2009.04.024

78. Reimer, B., Mehler, B., Coughlin, J. F., Roy, N., \& Dusek, J. A. (2011). The impact of a naturalistic hands-free cellular phone task on heart rate and simulated driving performance in two age groups. Transportation Research Part F: Traffic Psychology and Behaviour, 14(1), 13-25. https://doi.org/10.1016/ j.trf.2010.09.002.

79. Rimini-Doering, M., Manstetten, D., Altmueller, T., Ladstaetter, U., \& Mahler, M. (2001). Monitoring driver drowsiness and stress in a driving simulator. In Proceedings of the first international driving symposium on human factors in driver assessment, training and vehicle design (pp. 58-63). https://doi.org/10. 17077/drivingassessment.1009.

80. Rossi, R., Gastaldi, M., \& Gecchele, G. (2011). Analysis of driver task-related fatigue using driving simulator experiments. Procedia - Social and Behavioral Sciences, 20, 666-675. https://doi.org/10.1016/j.sbspro.2011.08.074.

81. Saifuzzaman, M., Haque, M. M., Zheng, Z., \& Washington, S. (2015). Impact of mobile phone use on car-following behaviour of young drivers. Accident; Analysis and Prevention, 82, 10-19. https://doi.org/10.1016/j.aap.2015.05.001.

82. Saxby, D., Matthews, G., Hitchcock, E., \& Warm, J. (2007). Development of active and passive fatigue manipulations using a driving simulator. In Proceedings of the human factors and Ergonoics society 51 st annual meeting (pp. 1237-1241).

83. Schmidt, E. A., Schrauf, M., Simon, M., Fritzsche, M., Buchner, A., \& Kincses, W. E. (2009). Drivers' misjudgement of vigilance state during prolonged monotonous daytime driving. Accident; Analysis and Prevention, 41(5), 10871093. https://doi.org/10.1016/.j.aap.2009.06.007.

84. Schmidt, E., \& Bullinger, A. C. (2017). Mitigating passive fatigue during monotonous drives with thermal stimuli: Insights into the effect of different stimulation durations. In Accident; analysis and prevention. Advance online publication. https://doi.org/10.1016/j.aap.2017.12.005.

85. Schroeter, R., Oxtoby, J., \& Johnson, D. (2014). AR and gamification concepts to reduce driver boredom and risk taking Behaviours. In L. N. Boyle (Ed.), The 6th international conference (pp. 1-8). https://doi.org/10.1145/2667317. 2667415.

86. Seaborn, K., Fels, D. I. (2015). Gamification in theory and action: A survey. In: International Journal of Human-Computer Studies 74, S. 14-31. https://doi. org/10.1016/j.jihcs.2014.09.006.

87. Simon, M., Schmidt, E. A., Kincses, W. E., Fritzsche, M., Bruns, A., Aufmuth, C., et al. (2011). EEG alpha spindle measures as indicators of driver fatigue under real traffic conditions. Clinical Neurophysiology, 122(6), 1168-1178. https://doi.org/10.1016/j.clinph.2010.10.044.

88. Sohn, S. Y., \& Stepleman, R. (1998). Meta-analysis on total braking time Ergonomics, 41(8), 1129-1140. https://doi.org/10.1080/001401398186432.

89. Steinberger, F., Schroeter, R., \& Watling, C. N. (2017). From road distraction to safe driving: Evaluating the effects of boredom and gamification on driving behaviour, physiological arousal, and subjective experience. Computers in Human Behavior, 75, 714-726. https://doi.org/10.1016/j.chb. 2017.06.019.
90. Stern, J. A., Schroeder, D. J., \& Stroliarov, N. (1996). Blinks, saccades, and fixation pauses during vigilance task performance: II. In Gender and time of day. Washington, D.C: U.S. Department of Transportation Retrieved from website: https:/www.faa.gov/data_research/research/med_humanfacs/ oamtechreports/1990s/media/am96-09.pdf.

91. Stutts, J. C., Wilkins, J. W., Scott Osberg, J., \& Vaughn, B. V. (2003). Driver risk factors for sleep-related crashes. Accident; Analysis and Prevention, 35(3), 321-331. https://doi.org/10.1016/S0001-4575(02)00007-6.

92. Temming, D.I. J. (2003). Fahrzeugklimatisierung und Verkehrssicherheit: Auswirkungen sommerlichen Klimas in Kfz auf die Leistungsfähigkeit der Fahrer. FAT-Schriftenreihe, 177, 319.

93. Thiffault, P., \& Bergeron, J. (2003). Monotony of road environment and driver fatique: A simulator study. Accident; Analysis and Prevention, 35(3), 381-391. https://doi.org/10.1016/50001-4575(02)00014-3.

94. Ting, P.-H., Hwang, J.-R., Doong, J.-L., \& Jeng, M.-C. (2008). Driver fatigue and highway driving: A simulator study. Physiology \& Behavior, 94(3), 448-453. https://doi.org/10.1016/j.physbeh.2008.02.015.

95. Tjolleng, A., Jung, K., Hong, W., Lee, W., Lee, B., You, H., et al. (2017). Classification of a driver's cognitive workload levels using artificial neural network on ECG signals. Applied Ergonomics, 59(Part A), 326-332. https://doi. org/10.1016/j.apergo.2016.09.013.

96. de Valck, E., \& Cluydts, R. (2001). Slow-release caffeine as a countermeasure to driver sleepiness induced by partial sleep deprivation. Journal of Sleep Research, 10(3), 203-209. https://doi.org/10.1046/j.1365-2869.2001.00260.x.

97. Vanlaar, W., Simpson, H., Mayhew, D., \& Robertson, R. (2008). Fatigued and drowsy driving: A survey of attitudes, opinions and behaviors. Journal of Safety Research, 39(3), 303-309. https://doi.org/10.1016/j.jsr.2007.12.007.

98. Verwey, W. B., \& Zaidel, D. M. (1999). Preventing drowsiness accidents by an alertness maintenance device. Accident; Analysis and Prevention, 31(3), 199211. https://doi.org/10.1016/S0001-4575(98)00062-1.

99. Vollrath, M., Meilinger, T., \& Krüger, H.P. (2002). How the presence of passengers influences the risk of a collision with another vehicle. Accident; Analysis and Prevention, 34(5), 649-654. https://doi.org/10.1016/500014575(01)00064-1.

100. Vossel, G. (1990). Elektrodermale Labilität: Ein Beitrag zur differentiellen Psychophysiologie. Zugl.: Mainz, Univ., Habil.-Schr. Göttingen: Verl. für Psychologie Hogrefe.

101. Waard, D. d. (1996). The measurement of drivers' mental workload @Groningen, Univ., Diss., 1996.

102. Wallner, C. (2013). Verhältnis- und Verhaltensprävention Retrieved from http:// www.fgoe.org/gesundheitsfoerderung/glossar/verhaltenspravention-undverhaltnispravention.

103. WHO. (2015). Global status report on road safety 2015: Supporting a decade of action. Geneva: WHO.

104. Wierwille, W. W., Ellsworth, L. A., Wreggit, S. S., Fairbanks, R. J., \& Kirn, C. L. (1994). Research on vehicle-based driver status/performance monitoring: Development, validation, and refinement of algorithms for detection of driver drowsiness.

105. Young, M. S., \& Stanton, N. A. (2007). What's skill got to do with it? Vehicle automation and driver mental workload. Ergonomics, 50(8), 1324-1339. https://doi.org/10.1080/00140130701318855.

106. Zhang, Y., Antonsson, E. K., \& Grote, K. (2006). A new threat assessment measure for collision avoidance systems. In Proceedings / 2006 IEEE intelligent transportation systems conference, 2006: Sept. 17-20, 2006, [Toronto, Ontario, Canada] (pp. 968-975). Piscataway: IEEE Operations Center. https:// doi.org/10.1109//TSC.2006.1706870.

\section{Publisher's Note}

Springer Nature remains neutral with regard to jurisdictional claims in published maps and institutional affiliations. 